\title{
SISTEMA FINANCIERO Y CRECIMIENTO ECONÓMICO EN CHILE ${ }^{1}$
}

\author{
Leonardo Hernández \\ y Fernando Parro
}

\begin{abstract}
Este trabajo presenta una breve descripción del grado de desarrollo de los mercados financieros en Chile, en comparación con otros países. Luego de resumir las principales reformas financieras implementadas en el país en las últimas décadas, se destacan las fortalezas y debilidades más importantes de los mercados financieros en Chile. A continuación se analizan los problemas urgentes, en particular la liquidez del mercado accionario, los mercados de derivados financieros y el mercado de capital de riesgo, y se discute si las reformas más recientes y las propuestas resuelven adecuadamente estos problemas.
\end{abstract}

Leonardo Hernández. Ingeniero Comercial y Magíster en Economía, Pontificia Universidad Católica de Chile. M. A. y Ph. D., Universidad de Columbia. Gerente asesor de la Presidencia, Banco Central de Chile.

Fernando Parro. Ingeniero Comercial y Magíster en Economía, Pontificia Universidad Católica de Chile. Economista, Departamento de Estudios, Banco Central de Chile.

${ }^{1}$ Las opiniones expresadas en este trabajo son las de los autores y no deben atribuirse al Banco Central de Chile o a sus autoridades. Agradecemos los valiosos comentarios de Elías Albagli, Luis Felipe Céspedes, José De Gregorio, Rodrigo Fuentes, Manuel Marfán, Klaus Schmidt-Hebbel y un árbitro anónimo. 


\section{Introducción y motivación}

$\mathrm{P}_{\mathrm{o}}$ or años se ha sabido que el desarrollo económico y el del sistema financiero van de la mano; esto es, como lo muestra el Gráfico $\mathrm{N}^{\circ} 1$, que los países de mayor ingreso tienen sistemas financieros más profundos o desarrollados.

Sin embargo, la discusión acerca de la causalidad entre el desarrollo del sistema financiero y el crecimiento económico ha generado por muchos años debate entre los economistas. Por una parte, el premio Nobel Robert Lucas (1988) desestimó el rol del sistema financiero como un determinante principal del crecimiento económico. Del mismo modo, la destacada economista Joan Robinson (1952) argumentó que "donde las empresas lideran, las finanzas siguen”. En esta perspectiva las finanzas no causan el crecimiento económico, sino que responden automáticamente a los cambios en demanda del sector real. Por otra parte, el también ganador del Nobel Merton Miller (1998) argumentó que "la proposición de que los mercados financieros contribuyen al crecimiento económico es demasiado obvia como para $\begin{array}{ll}\text { GRAFÍCO No 1: } & \text { RELACIÓN ENTRE DESARROLLO FINANCIERO Y DESARROLLO } \\ \text { ECONÓMICO (83 países) }\end{array}$

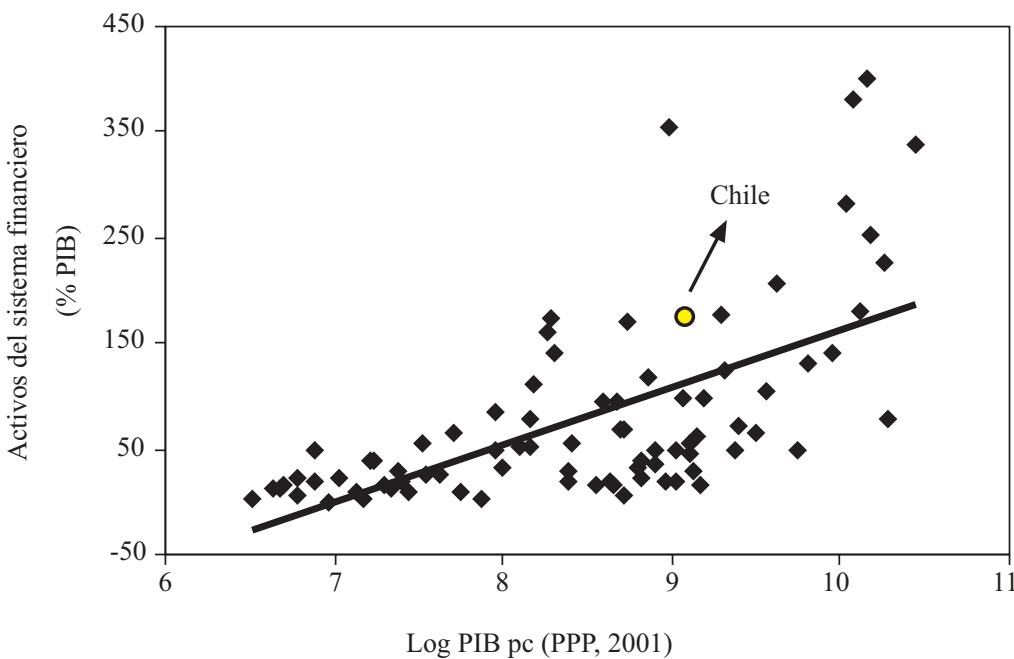

Nota: Los activos del sistema financiero incluyen los pasivos líquidos del sistema bancario, la capitalización del mercado accionario, los bonos privados domésticos y los bonos públicos domésticos.

Fuente: Beck, Demirguç-Kunt y Levine (2003). 
una discusión seria”. De manera similar, Bagehot (1873), Schumpeter (1934), Gurley y Shaw (1955), Goldsmith (1969) y McKinnon (1973) han rechazado la idea de que el nexo entre finanzas y crecimiento pueda ser ignorado sin obstaculizar nuestro entendimiento del proceso de crecimiento económico. Más recientemente, una serie de trabajos de investigación iniciados por Levine (1997) indica que los sistemas financieros juegan un rol crítico en estimular el crecimiento económico.

Todos estos antecedentes justifican preguntarse si el desarrollo del sistema financiero importa para el crecimiento. Avanzar en entender el rol que juega el sistema financiero en el proceso de crecimiento económico permite comprender de mejor manera este último y, finalmente, influir en la elección de políticas públicas, ya que éstas — sean de índole macroeconómica, impositiva, legal o regulatoria— configuran la operación y evolución del sistema financiero.

La estructura de este paper es la siguiente: la sección II revisa la literatura teórica (sección II.1) y empírica (sección II.2) acerca del nexo entre desarrollo financiero y crecimiento económico. La sección III revisa el desarrollo financiero en Chile, los principales cambios de los últimos treinta años (sección III.1), el nivel de desarrollo del sistema financiero comparado con otras economías (sección III.2), y los efectos del desarrollo financiero sobre el crecimiento en Chile (sección III.3). La sección IV evalúa las propuestas recientes de reformas al sistema financiero chileno y la sección $\mathrm{V}$ presenta las principales conclusiones que surgen del trabajo.

\section{Relación entre desarrollo financiero y crecimiento: ¿Qué sabemos?}

Hay una abundante literatura que investiga la relación entre el sistema financiero y el crecimiento de la economía. Los trabajos de investigación se componen tanto de modelos teóricos como de trabajos empíricos, que buscan establecer qué tipo de vínculo existe entre el desarrollo financiero y el desarrollo económico. A continuación revisamos brevemente la literatura teórica y empírica con el objetivo de extraer las principales conclusiones encontradas acerca de este vínculo.

\section{II.1. Relación entre desarrollo financiero y crecimiento: Teoría}

Los costos de adquirir información, hacer cumplir los contratos y llevar a cabo transacciones generan incentivos para el surgimiento de mercados, intermediarios y contratos financieros. En otras palabras, los siste- 
mas financieros surgen con el propósito de reducir los costos y minimizar las fricciones y asimetrías que existen en los mercados. El modo en que estos problemas se resuelven influye en las decisiones de ahorro e inversión, y afectan a la asignación de recursos de las economías y al crecimiento económico ${ }^{2}$.

Analíticamente se pueden distinguir cinco funciones que presta el sistema financiero a las economías, a través de las cuales reduce los costos de transacción, de obtención de información y de hacer cumplir los contratos (Levine, 2004):

- Producción de información ex ante acerca de las posibles inversiones y asignaciones de capital.

- Monitoreo de las inversiones realizadas y de los gobiernos corporativos.

- Comercialización, diversificación y administración de riesgos.

Movilización de ahorros.

- Provisión de medios de pagos para facilitar el intercambio de bienes y servicios.

Así, un mayor grado de desarrollo financiero implica que cada una de las cinco funciones anteriores se encuentren más diseminadas y/o sean de mejor calidad, lo que conlleva menores costos de adquisición de información y realización de transacciones y una mejor selección de proyectos de inversión. A su vez, al eliminar de mejor forma las fricciones de mercado aludidas, el desarrollo financiero aumentará la rentabilidad y/o disminuirá la incertidumbre asociada a las distintas alternativas de inversión, lo que influirá positivamente en las decisiones de ahorro e inversión, mejorando la asignación de recursos en la economía e incentivando el crecimiento econó$\operatorname{mico}^{3}$.

\footnotetext{
${ }^{2}$ Hay que notar, sin embargo, que el desarrollo financiero no sólo permite un mayor crecimiento en el largo plazo, sino que también permite suavizar los ciclos económicos. Dicho de otro modo, una ventaja de contar con un sistema financiero más desarrollado es que éste permite suavizar las fluctuaciones de la economía, por ejemplo, permitiendo el acceso a endeudamiento en períodos malos.

${ }^{3}$ Cabe destacar que las tres primeras funciones, que se asocian a una mejor selección de proyectos con mejoras en productividad y sostenidas ganancias en eficiencia, son el mecanismo de transmisión más importante entre desarrollo financiero y crecimiento (más importante aun que la simple acumulación de recursos). Sin embargo, existen otros mecanismos de segundo orden y, por ende, menos importantes que pueden hacer más complicada esta relación. A modo de ejemplo, Japelli y Pagano (1994) explican que la liberalización financiera en el mercado de los créditos de consumo y de créditos hipotecarios puede tener un efecto negativo sobre el crecimiento, ya que al aliviar las restricciones de liquidez de las personas se reducen los incentivos al ahorro de éstas. Por el contrario, De Gregorio (1996) argumenta que las restricciones de liquidez pueden tener un efecto negativo sobre el crecimiento al reducir la acumulación de capital humano.
} 
Un aspecto relacionado con este capítulo y que merece mención se refiere a cómo lograr un mayor desarrollo de los sistemas financieros. La Porta et al. (1997) muestran que en el largo plazo variables institucionales, como el imperio de la ley y la protección de los derechos de los acreedores, son importantes determinantes del financiamiento externo de las firmas ${ }^{4}$. En otras palabras, los determinantes últimos del desarrollo financiero son variables de tipo institucional.

\section{II.2. Relación entre desarrollo financiero y crecimiento: Evidencia empírica}

Existe una amplia literatura empírica que investiga el nexo entre desarrollo económico y desarrollo financiero. La línea de investigación seguida en este tema ha estado destinada principalmente a establecer la causalidad subyacente en este nexo, identificar los mecanismos de transmisión del vínculo, y establecer si es mejor que los sistemas financieros se desarrollen a través del sistema bancario o del mercado financiero no bancario (bolsas de valores). Por otra parte, la literatura empírica también se compone de una amplia variedad de enfoques y técnicas estadísticas: estudios de corte transversal, paneles, análisis de series de tiempo, estudios a nivel de industrias y estudios a nivel de firmas ${ }^{5}$. A continuación describimos brevemente los principales resultados encontrados en la literatura que investiga la relación entre desarrollo financiero y crecimiento económico. El Cuadro N ${ }^{\circ} 1$ presenta una descripción más detallada de los estudios revisados.

Una primera serie de estudios de corte transversal (Goldsmith, 1969; King y Levine, 1993; Levine y Zervos, 1998) reveló que el desarrollo financiero precede al crecimiento del producto. Trabajos posteriores que utilizaron técnicas estadísticas más sofisticadas, como el Método de Variables Instrumentales (Levine, Loayza y Beck, 2000) y de Paneles Dinámicos (Beck, Levine y Loayza, 2000; y Beck y Levine, 2004), concluyeron que el desarrollo financiero causa el crecimiento económico en el largo plazo y, además, el efecto del mismo sobre el crecimiento del producto per cápita es económicamente significativo.

${ }^{4}$ Financiamiento interno se refiere al monto de inversión que una firma financia con fuentes propias, como es el flujo de caja generado por la misma operación. El financiamiento externo, como indica su nombre, se refiere a fuentes de financiamiento como la emisión de deuda o a acciones.

${ }^{5}$ Un estudio de corte transversal es aquel que se compone de una unidad de tiempo (por ejemplo, la tasa de crecimiento promedio de la economía entre 1960 y 2000) y varias unidades "transversales", como las muestras de varios países. Un estudio de series de tiempo es aquel que tiene varias unidades de tiempo y una única unidad transversal (por ejemplo, estudios acerca de un país para un número determinado de años). Finalmente, un estudio de panel es aquel que se compone de varias unidades de tiempo y transversales (con datos de varios países y varios años para cada uno de ellos). 


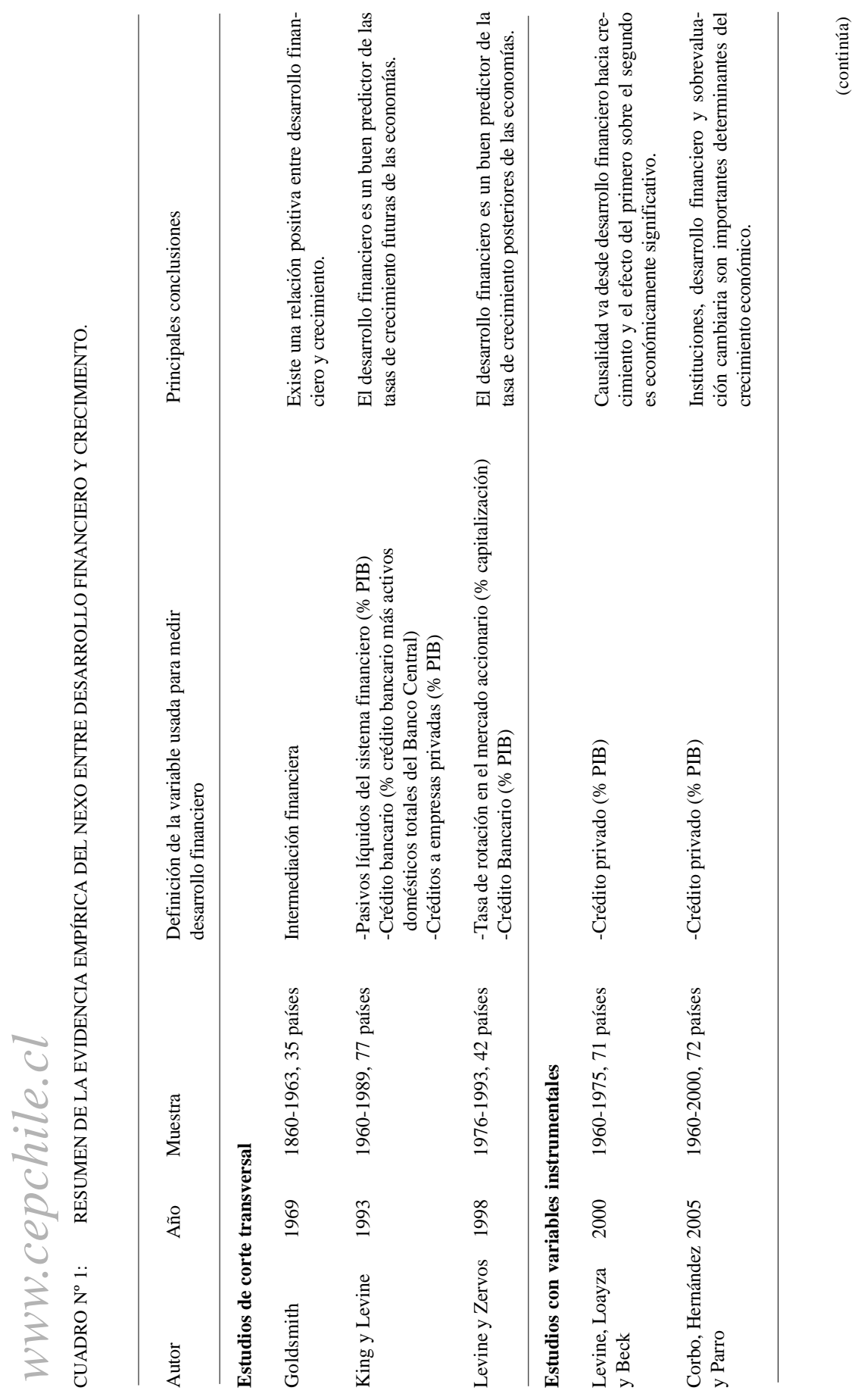




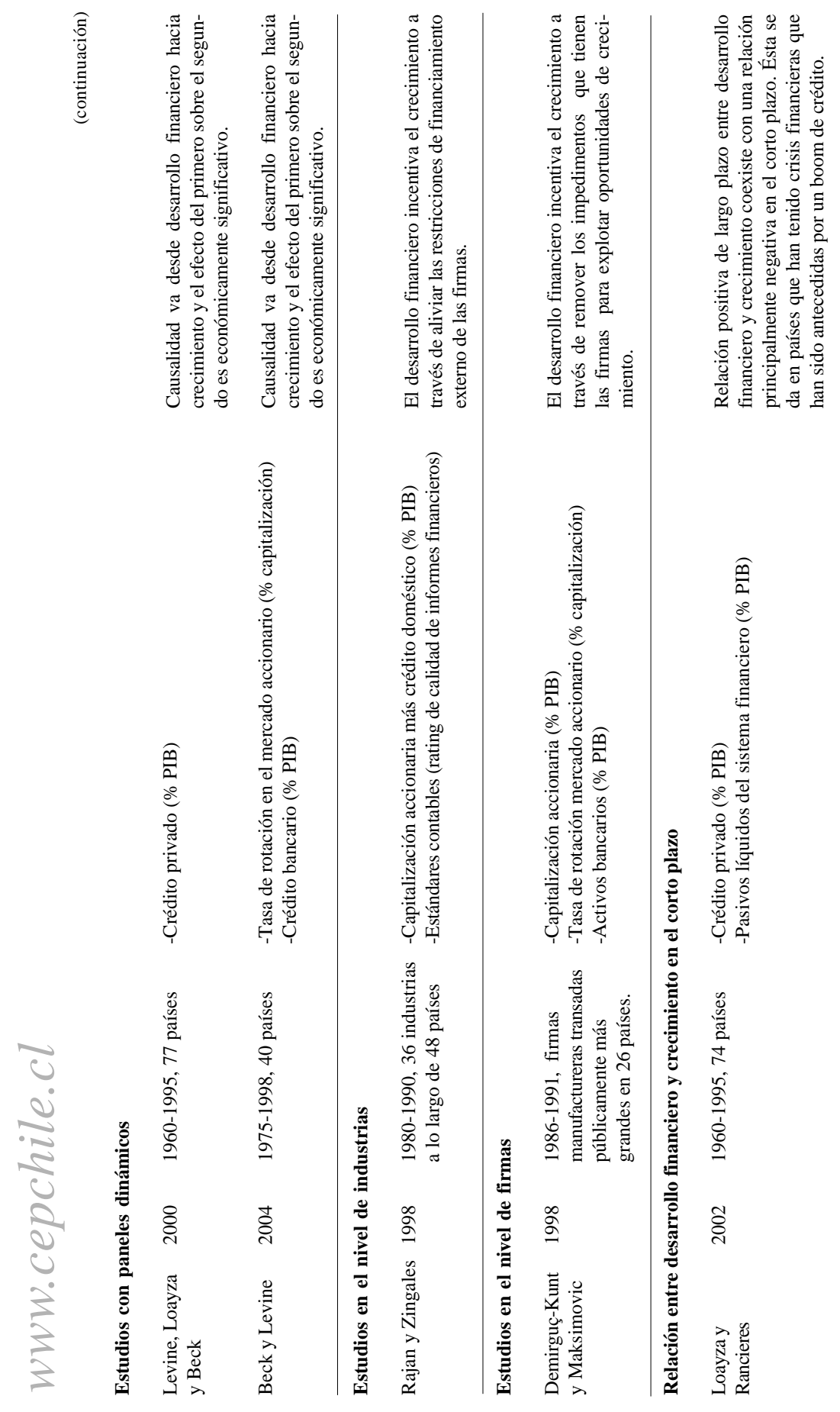


Corbo, Hernández y Parro (2005), en un estudio de corte transversal, analizan el rol de las instituciones y las políticas en el crecimiento económico. Las estimaciones arrojan como resultado que, una vez que se toma en cuenta la calidad de las instituciones, variables de política como el grado de apertura y gasto de gobierno no son importantes (no resultan estadísticamente significativas). Sin embargo, el grado de desarrollo financiero es un determinante significativo e importante del crecimiento, aunque su significancia económica resulta menor que lo reportado en estudios previos. Utilizando estas estimaciones estos autores muestran que casi el $65 \%$ de la diferencia de crecimiento entre Asia y América Latina durante la década de los 90 se debe a la diferencia en el desarrollo financiero entre ambas regiones.

Una serie de trabajos recientes con datos microeconómicos, tanto en el nivel de industrias (Rajan y Zingales, 1998) como de firmas (DemirguçKunt y Maksimovic, 1998), muestran cómo un sistema financiero más desarrollado ayuda a eliminar las fricciones (imperfecciones) de mercado mencionadas más arriba. En particular, un mayor desarrollo financiero reduce la brecha entre el costo de conseguir financiamiento interno y externo para la firma ${ }^{6}$. De este modo, el desarrollo financiero ayuda al crecimiento económico a través de remover los impedimentos que tienen las firmas para conseguir financiamiento y explotar sus oportunidades de inversión, facilitando, por ende, el crecimiento y la formación de nuevas firmas.

Otra serie de trabajos se ha focalizado en evaluar si es mejor desarrollar los sistemas financieros a través de los bancos o del mercado financiero no bancario. La evidencia en este punto no es concluyente: trabajos de Demirguç-Kunt y Levine (2001a, 2001b), Levine (2002), Tadesse (2002), Beck y Levine (2002), y Carlin y Mayer (2003) encuentran que no es relevante la estructura del sistema financiero para el crecimiento económico. En resumen, los estudios revisados muestran que:

- El desarrollo financiero causa el crecimiento económico en el largo plazo y el impacto de éste es económicamente significativo ${ }^{7-8}$.

${ }^{6}$ Ver nota 4

${ }^{7}$ A modo de ejemplo, Levine, Loayza y Beck (2000) estiman que si el crédito privado como porcentaje del PIB en México sobre el período 1960-1995 (22,9\%) hubiera sido el del promedio de los países en su muestra (27,5\%), el PIB per cápita habría crecido en México 0,4\% más por año (esto es, el PIB per cápita en 1995 habría sido $15 \%$ más alto). A su vez, si el crédito privado como porcentaje del PIB en India sobre el período 1960-1995 (19,5\%) hubiera sido el del promedio de los países en desarrollo de la muestra (25\%), el PIB per cápita habría crecido en India 0,6\% más por año (el PIB per cápita en 1995 habría sido 24\% más alto que lo que fue).

${ }^{8}$ De Gregorio y Guidotti (1995) presentan como evidencia que, mientras para un corte transversal para una muestra amplia de países, la intermediación financiera tiene un efecto positivo en el crecimiento económico, para un panel que incluye sólo países de América Latina, los cuales han estado expuestos a crisis financieras, esta relación es 
- El desarrollo financiero contribuye al crecimiento al facilitar a las firmas la explotación de nuevas oportunidades de inversión.

- No importa si los países desarrollan los sistemas financieros a través del sistema bancario o a través del mercado financiero no bancario.

\section{Desarrollo financiero en Chile}

\section{III.1. Breve reseña y desarrollos recientes}

A comienzos de los setenta la economía chilena se caracterizaba por estar cerrada al comercio mundial y por presentar un alto grado de intervención estatal. El sector financiero no era la excepción: existía un control estricto sobre las tasas de interés, sobre la asignación del crédito y gran parte del sistema bancario estaba en manos del Estado. A partir de 1974 se liberalizaron las tasas de interés, se eliminaron los controles al crédito y se privatizó gran parte del sector bancario. Sin embargo, este proceso de liberalización financiera no se vio acompañado de un marco de regulación y supervisión apropiado, lo cual fue un determinante clave para desencadenar la crisis financiera de 1982-1983.

Con posterioridad a la crisis se produjo una revisión de las instituciones existentes: en 1986 se introdujo una nueva Ley de Bancos, orientada a mejorar el marco de supervisión y regulación del sistema financiero, y una nueva Ley de Quiebras.

En 1981, previo a la crisis y en un hito histórico para el sistema financiero chileno, se llevó a cabo la reforma de pensiones, donde el sistema de reparto existente entonces fue cambiado por un sistema de capitalización individual —Corbo y Schmidt-Hebbel (2003) estiman que más de 30\% del desarrollo financiero ocurrido en Chile entre 1981 y 2001 se debió a esta reforma-.

negativa. Loayza y Rancieres (2002) encuentran una relación negativa entre el grado de intermediación financiera y el crecimiento económico alrededor de las crisis financieras. Estos trabajos, junto con la evidencia presentada en este capítulo, resaltan el hecho de que un mayor desarrollo financiero no siempre es deseable y conducente a mayor crecimiento. En particular, los procesos de liberalización y profundización financiera en los países, si no se ven acompañados de un marco de regulación y supervisión apropiados, pueden desencadenar crisis financieras. Un claro ejemplo de esta situación es la crisis financiera de Chile de 1982-1983 (ver sección III.1).

${ }^{9}$ Como se mencionó en la nota 8, el desarrollo que se observa después de un proceso de liberalización financiera, si no está acompañado de un marco de regulación y supervisón adecuados, casi siempre da origen a intermediación financiera de mala calidad y desencadena en crisis. 
A partir del año 1986 el sistema financiero comienza un período de liberalización y profundización: se autoriza la inversión de los Fondos de Capitales Extranjeros (FICE), se promulga una nueva Ley de Bancos en 1997, que entre otras cosas autoriza la internacionalización de la banca; se desregula la industria de fondos mutuos y seguros y se adoptan estándares internacionales en materia de supervisión (Acuerdo de Basilea I). Además, en 1994-1995 se autoriza el financiamiento privado de proyectos de infraestructura públicos (caminos, puentes, etc.) a través de concesiones de largo plazo, se incentiva la exportación de capitales desde Chile, y se permiten nuevas opciones de inversión para las AFP, entre otras reformas.

Pero Chile ha seguido avanzando en los últimos años en profundizar su sistema financiero, principalmente con medidas orientadas a mejorar la microestructura del mismo: en 2001 se promulgó la Ley de Opas, orientada principalmente a mejorar la protección de los accionistas minoritarios, y se implementó la Reforma al Mercado de Capitales I, que entregó incentivos tributarios al ahorro, desreguló la industria de fondos mutuos y de seguros, y autorizó los multifondos de pensiones, entre otras medidas. Además, actualmente se está trabajando en promulgar la Reforma al Mercado de Capitales II, que entre otras medidas pretende desarrollar la industria de capital de riesgo y perfecciona el régimen de gobiernos corporativos.

\section{III.2. El sistema financiero chileno hoy}

La transformación del sistema financiero chileno durante los últimos treinta años ha permitido un notable desarrollo del sistema bancario, mercado accionario y, más recientemente, de otros mercados. En lo que se refiere al sistema bancario, el tamaño de éste ha aumentado considerablemente luego de la crisis de 1982-1983 (ver Gráfico № 2). Los activos del sistema bancario representaban alrededor de $21 \%$ del producto el año 1979, mientras que al año 2001 este valor subió a 63,6\%. La eficiencia del sector bancario ha aumentado también en la última década, principalmente como consecuencia de la mayor competencia en el sector (ver Gráfico $\mathrm{N}^{\circ} 3$ ).

En cuanto al mercado accionario, el tamaño de éste ha tenido un explosivo crecimiento, principalmente a partir de mediados de los ochenta: en 1985 la capitalización del mercado representaba un 12\% del PIB, mientras que en 1995 ésta era un 110\% del PIB. Esta tendencia se ha visto parcialmente revertida en los últimos años; el año 2001 la capitalización de mercado alcanzaba 74,6\% del PIB (ver Gráfico $\mathrm{N}^{\circ}$ 4). Por otra parte, la liquidez del mercado accionario ha seguido básicamente la misma trayectoria: aumentó a partir de fines de los ochenta, pero disminuyó en los últimos años (ver Gráfico $N^{\circ}$ 5). 
GRÁFICO N 2: $\quad$ ACTIVOS TOTALES DEL SISTEMA BANCARIO

(\% PIB, 1979-2001)

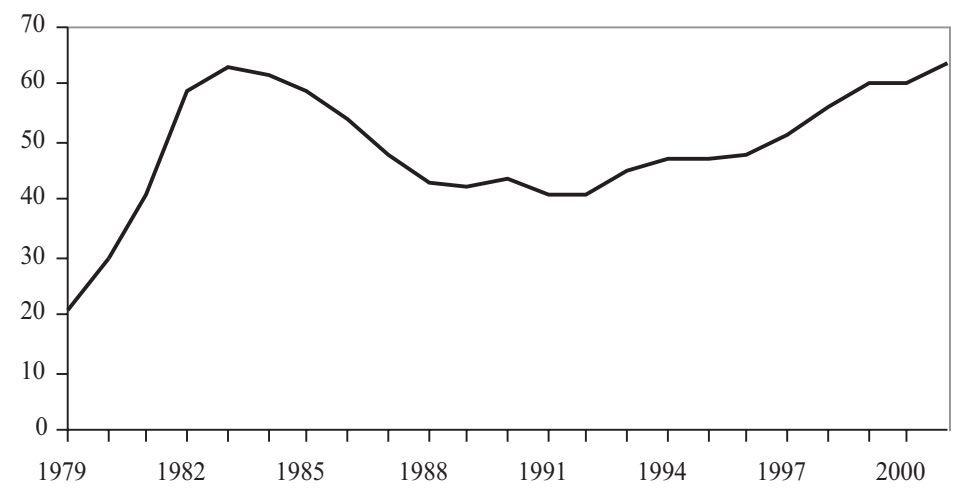

Activos del sector bancario (\% PIB)

Fuente: Beck, Demirguç-Kunt y Levine (2003).

GRÁFICO No 3: EFICIENCIA DEL SECTOR BANCARIO

(1992-2003)

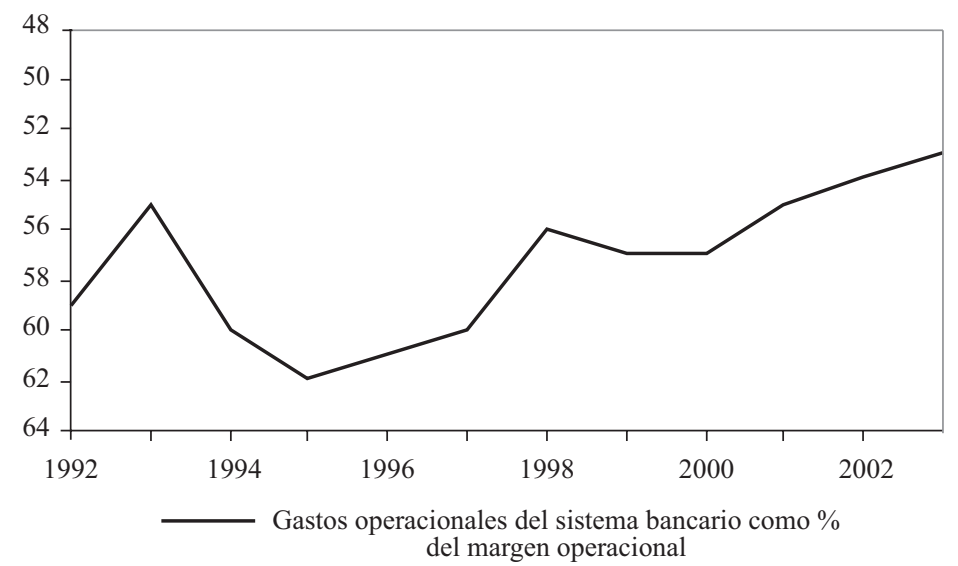

Fuente: Banco Central de Chile.

Pero Chile también ha desarrollado su sistema financiero a través de otros mercados, aunque estos desarrollos son sólo de los últimos años. El mercado de bonos corporativos ha tenido un alto crecimiento a partir del año 2000, con un stock al año 2003 de 13\% del PIB, más de cuatro veces el del año 1998 (ver Gráfico Nº 6). La industria de fondos mutuos también ha 
GRÁFICO N ${ }^{\circ}$ : CAPITALIZACIÓN DEL MERCADO ACCIONARIO

(\% PIB, 1979-2001)

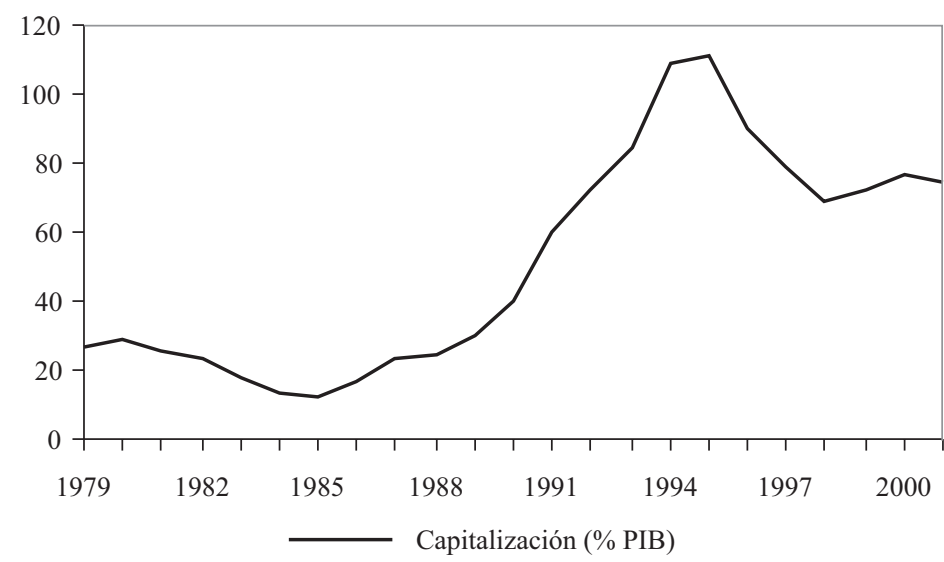

Fuente: Beck, Demirguç-Kunt y Levine (2003).

GRÁFICO N ${ }^{\circ}$ 5: LIQUIDEZ DEL MERCADO ACCIONARIO (1979-2001)

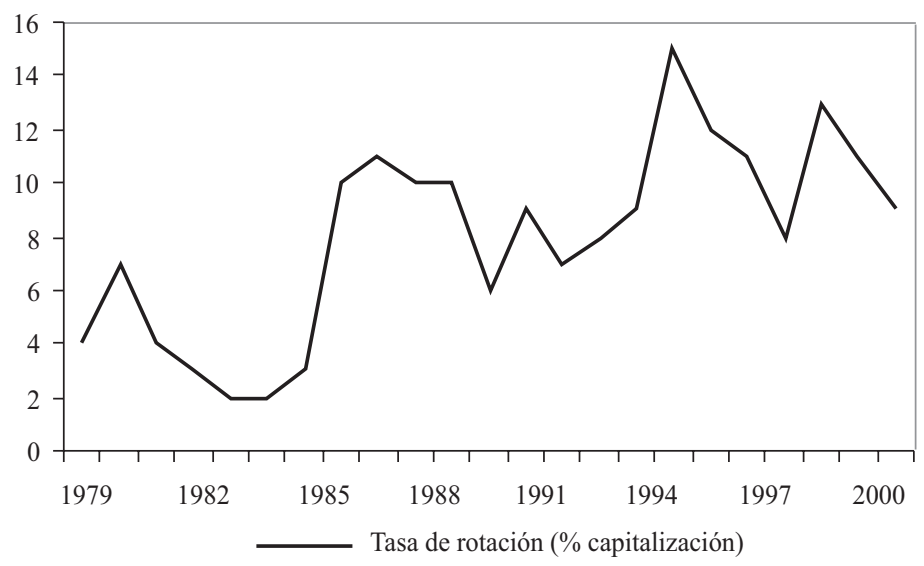

Fuente: Beck, Demirguç-Kunt y Levine (2003).

crecido notablemente durante los últimos cuatro años, tanto en número como en tipos de fondos (ver Gráfico $\mathrm{N}^{\circ} 7$ ). En cuanto a la industria de Fondos de Pensiones, ésta se ha desarrollado en forma sostenida desde principios de los ochenta: los activos mantenidos hoy representan un $60 \%$ del PIB y han alcanzado una alta diversificación (ver Gráficos Nos. 8 y 9). En 
GRÁFICO N ${ }^{\circ}$ 6: $\quad$ MERCADO DE BONOS CORPORATIVOS

(\% PIB, 1998-2003)

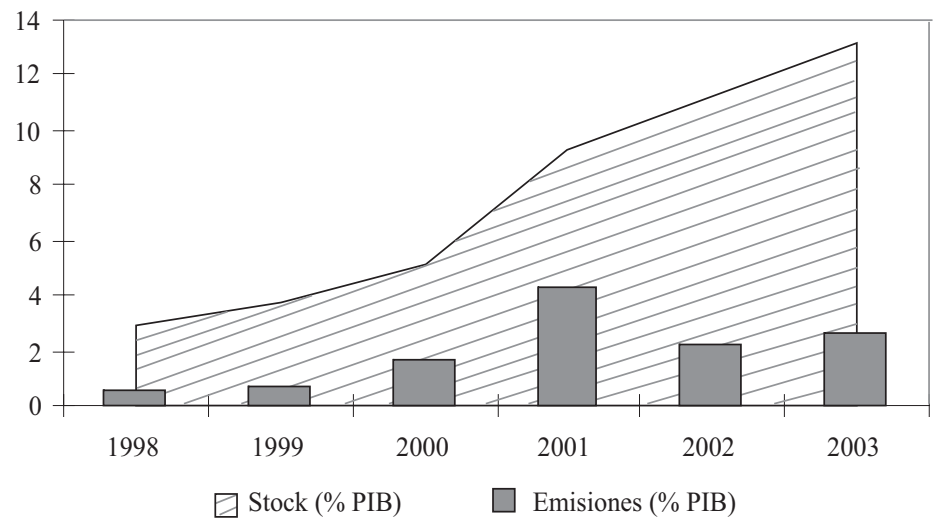

Fuente: Banco Central de Chile.

GRÁFICO N ${ }^{\circ}$ 7: $\quad$ NÚMERO Y TIPOS DE FONDOS MUTUOS

(1997-2003)

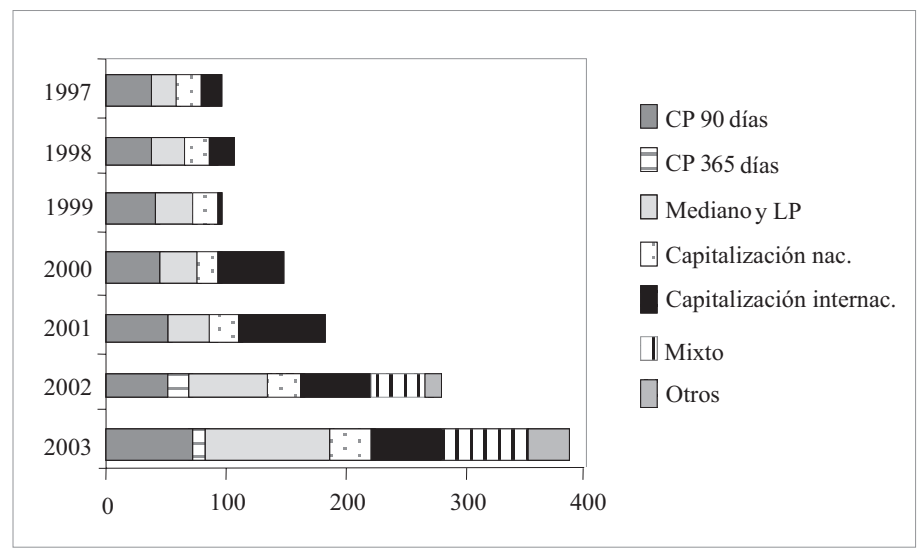

Fuente: Asociación de Administradoras de Fondos Mutuos.

general, los activos en manos de inversionistas institucionales hoy alcanzan más del 100\% del producto, comparado con sólo el 50\% a principios de los noventa.

Chile hoy tiene uno de los sistemas financieros más desarrollados (en cuanto a tamaño) entre las economías emergentes: los activos totales del sistema financiero representan alrededor de 1,7 veces el producto. Sin 
GRÁFICO No 8: $\quad$ DIVERSIFICACIÓN DE LOS FONDOS DE PENSIONES

(1982-2002)

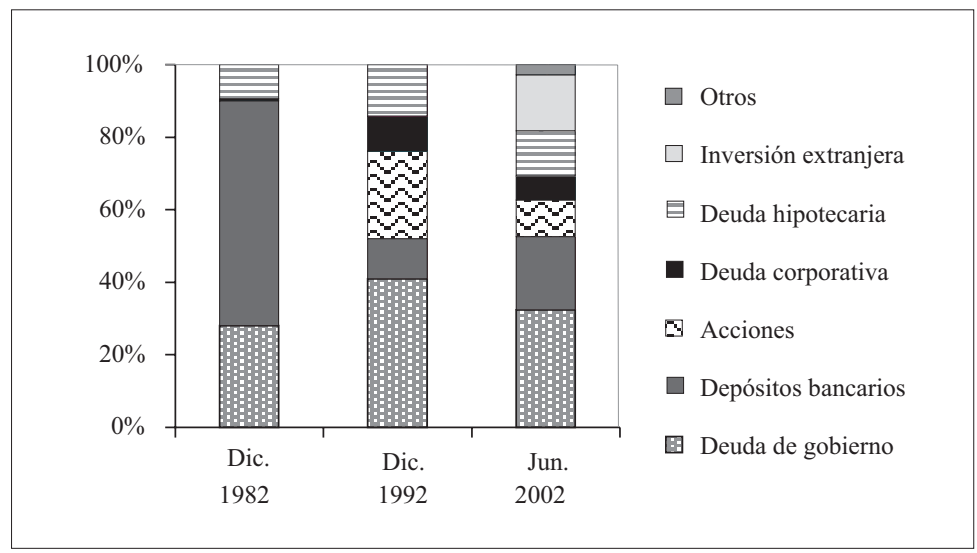

Fuente: Superintendencia de AFP.

GRÁFICO No 9: $\quad$ ACTIVOS EN MANOS DE INVERSIONISTAS INSTITUCIONALES

(\% PIB, 1981-2003)

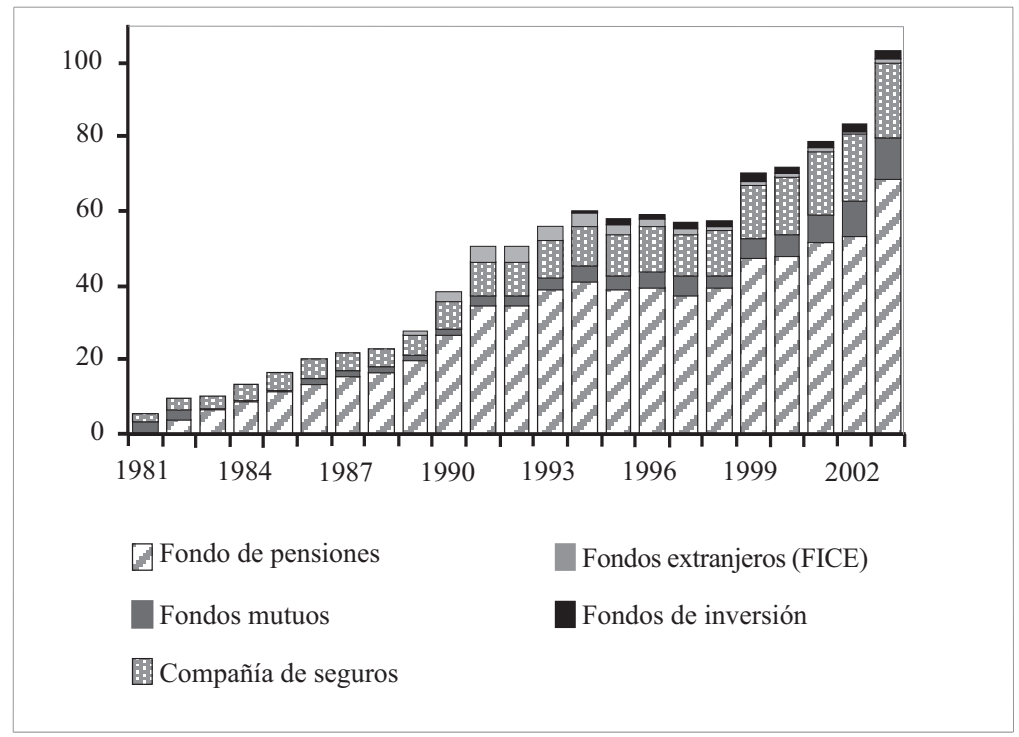

Fuente: Banco Central de Chile. 
GRÁFICO No 10: $\quad$ ACTIVOS TOTALES DEL SISTEMA FINANCIERO, 2001

(\% PIB, PAÍSES SELECCIONADOS)

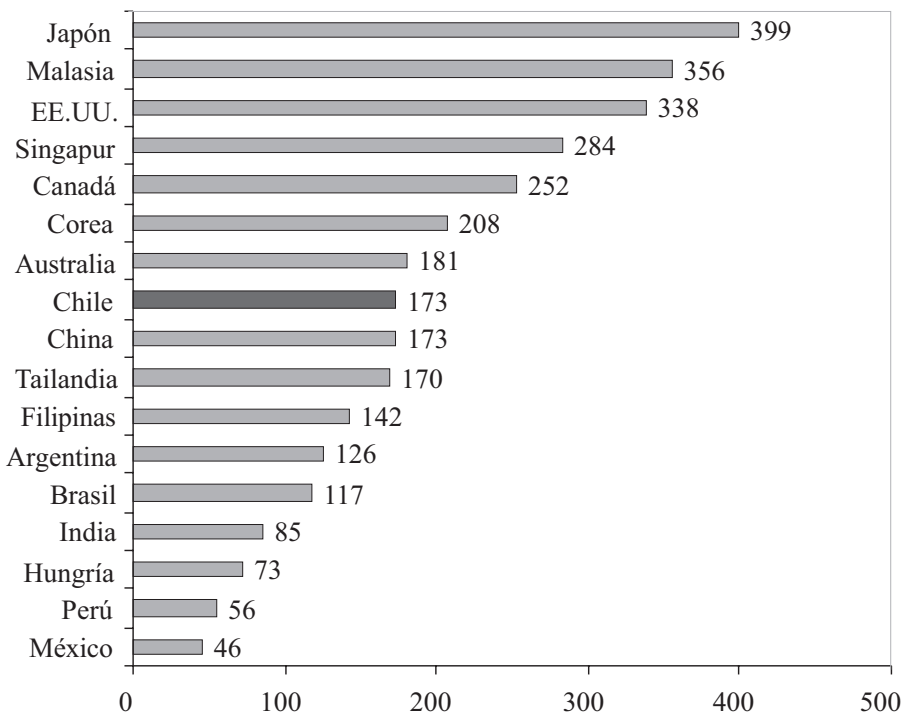

Nota: Los activos del sistema financiero incluyen los pasivos líquidos del sistema bancario, la capitalización del mercado accionario, los bonos privados domésticos y los bonos públicos domésticos.

Fuente: Beck, Demirguç-Kunt y Levine (2003).

embargo, todavía no se llega a los niveles de países asiáticos, como Japón, Malasia y Singapur, o de países desarrollados como Estados Unidos y Canadá (ver Gráfico No 10 ).

Conclusiones similares emergen al comparar distintas características del sistema bancario y el tamaño del mercado accionario con los del resto del mundo. El sistema bancario chileno es robusto, en relación con otras economías emergentes, aunque todavía no llega al nivel de países como Canadá, Estados Unidos y Portugal (ver Gráfico N ${ }^{\circ} 11$ ). La eficiencia del sector bancario es alta en relación con otros países de la región, aunque todavía no alcanza los niveles de economías más desarrolladas, como las de Australia, Corea, Tailandia y Nueva Zelanda (Bankscope, reportado en Fondo Monetario Internacional, 2004). En cuanto al tamaño del mercado accionario, Chile también está bien posicionado en comparación con otros países emergentes, aunque está por debajo de países como el Reino Unido, Malasia, Estados Unidos y Canadá (ver Gráfico No 12 ). 
GRÁFICO No 11: RANKING DE FORTALEZA DEL SISTEMA BANCARIO

(Países seleccionados)

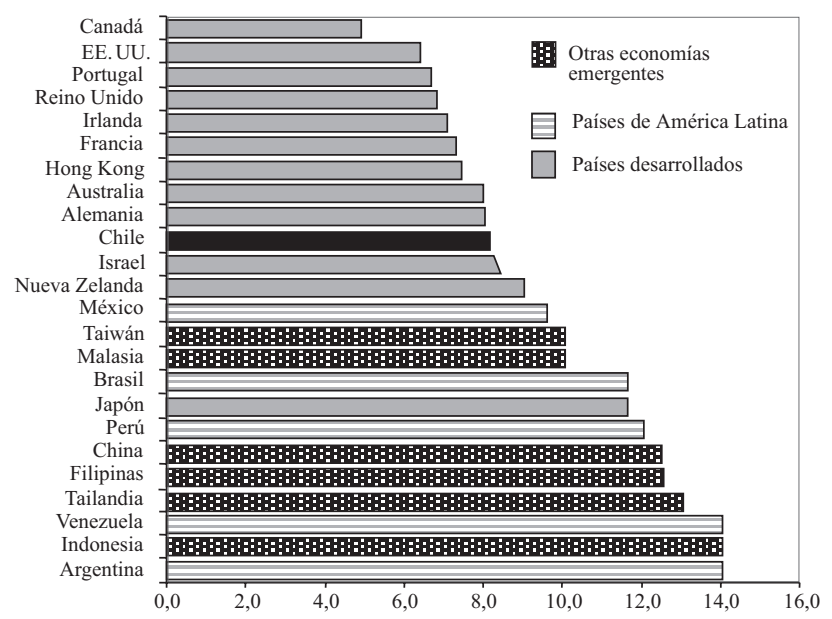

Nota: Un número mayor indica más debilidad del sistema bancario.

Fuente: Moody's (2004).

GRÁFICO No 12: CAPITALIZACIÓN DE MERCADO, 2001

(\% PIB, países seleccionados)

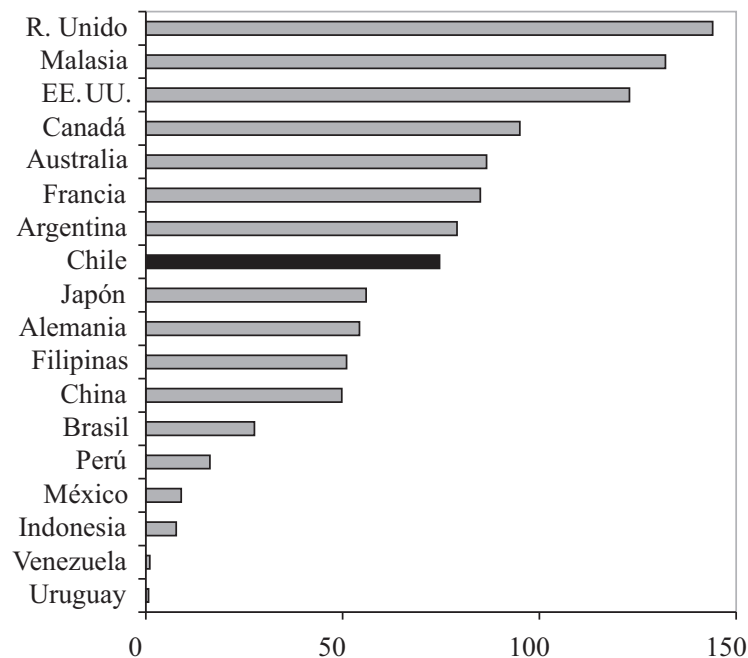

Fuente: Beck, Demirguç-Kunt y Levine (2003). 
GRÁFICO No 13: LIQUIDEZ DEL MERCADO ACCIONARIO, 2001

(Tasa de rotación, medida como \% de la capitalización, países seleccionados)

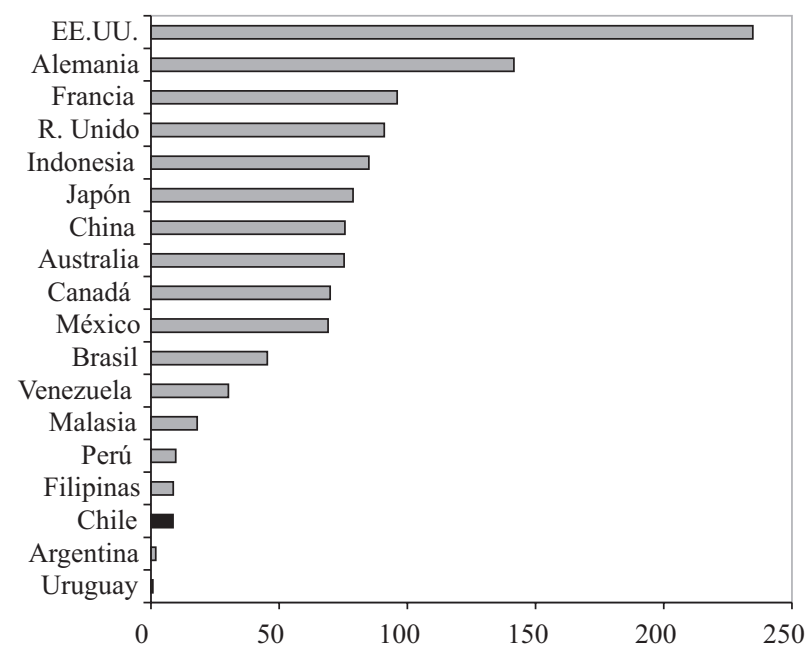

Fuente: Beck, Demirguç-Kunt y Levine (2003).

Sin embargo, Chile tiene un problema de iliquidez en su mercado accionario. Pese a que el mercado chileno es relativamente grande, es ilíquido, como lo muestra el Gráfico $\mathrm{N}^{\circ} 13$. De hecho, Chile tiene uno de los mercados accionarios más ilíquidos entre las economías emergentes ${ }^{10}$.

\section{III.3. Desarrollo financiero y crecimiento en Chile}

Dado el notable desarrollo del sistema financiero chileno en las últimas décadas, cabe preguntarse en qué medida éste ha contribuido al crecimiento económico del país.

Tomando los parámetros estimados en la literatura empírica se puede cuantificar este efecto, aunque medido sobre el crecimiento del producto per cápita. Como variable de desarrollo financiero tomamos la más comúnmente utilizada y que corresponde al crédito privado como porcentaje del

${ }^{10}$ Esta conclusión no cambia aún si se consideran las transacciones de ADR en otras bolsas, las cuales representan un $50 \%$ de las transacciones totales de las firmas chilenas que han emitido estos instrumentos. 
PIB (el Gráfico No 14 muestra la evolución de esta variable desde 1961). Se tomaron dos períodos representativos: el primero abarca desde 1961 hasta 2001 e incluye el período de liberalización del sistema financiero, la crisis financiera de 1982-1983 y el período de profundización y alto crecimiento desde mediados de los ochenta. El segundo período abarca desde 1986 hasta 2001 e incluye sólo el período de profundización y alto crecimiento del sistema financiero.

GRÁFICO No 14: CRÉDITO PRIVADO

(\% PIB, 1961-2001)

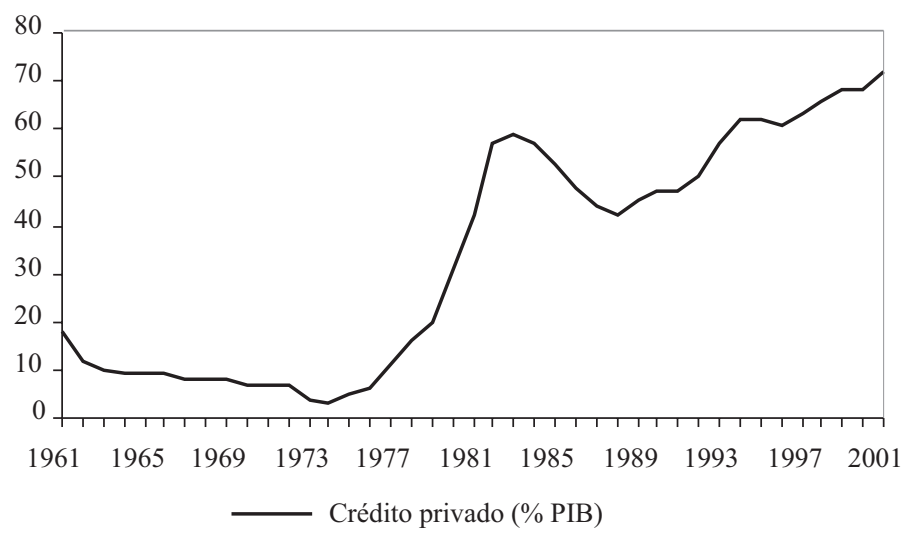

Fuente: Beck, Demirguç-Kunt y Levine (2003)

Como lo muestra el Gráfico $N^{\circ}$ 15, el desarrollo financiero aportó de manera significativa al crecimiento del producto per cápita entre 1961 y 2001. La tasa de crecimiento del producto per cápita durante este período fue de $2,7 \%$ anual, de los cuales $1,5 \%$ se explica por el desarrollo del sistema financiero. Al tomar el segundo período escogido, el aporte del desarrollo financiero al crecimiento aparece más modesto: del $5 \%$ que creció el producto per cápita entre 1986 y 2001, sólo 0,4\% lo explica el desarrollo financiero (el Cuadro $\mathrm{N}^{\circ} 2$ explica cómo se calcula la contribución al crecimiento del desarrollo financiero para ambos períodos). Esta contribución más modesta se debe a que el desarrollo financiero de Chile fue porcentualmente mayor en la primera parte de la muestra, aunque más volátil por la crisis de 1982-83, la que en parte se debió a una mala calidad de intermediación financiera producto de un marco de regulación y supervisión inadecuado. Estos problemas, que se corrigieron en la segunda mitad de los ochenta, permitieron el crecimiento sostenido observado desde $1986^{11}$.

11 Ver notas 8 y 9. 
GRÁFICO No 15: EFECTO DEL DESARROLLO FINANCIERO SOBRE EL CRECIMIENTO DEL PRODUCTO PER CÁPITA ANUAL EN CHILE

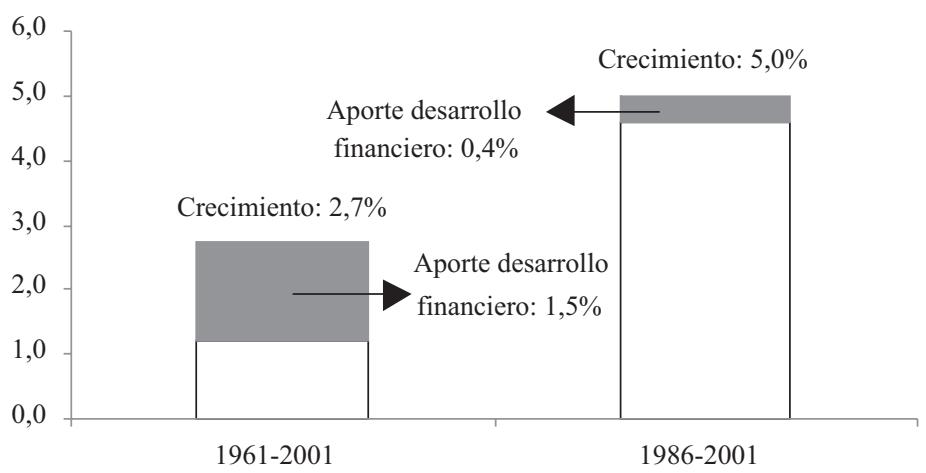

Fuente: Elaboración propia en base a parámetros estimados en Levine, Loayza y Beck (2000) y Beck, Levine y Loayza (2000). El Cuadro Nº 2 explica la obtención del efecto del desarrollo financiero sobre el crecimiento del producto per cápita anual en Chile.

\section{CUADRO N ${ }^{\circ}$ 2: $\quad$ ESTIMACIÓN DEL EFECTO DEL DESARROLLO FINANCIERO EN CHILE SOBRE EL CRECIMIENTO ECONÓMICO}

Para estimar el efecto del desarrollo financiero en Chile sobre el crecimiento del producto per cápita se procedió de la siguiente manera:

- El nivel de desarrollo financiero en Chile, medido como crédito privado como proporción del PIB, en 1961 era de 18,1\%.

- El desarrollo financiero promedio en Chile entre 1961 y 2001 fue de 33,7\%.

- El parámetro estimado en Levine, Loayza y Beck (2000), que mide el efecto marginal del desarrollo financiero sobre la tasa de crecimiento del producto per cápita, es de 2,5; mientras que el estimado en Beck, Levine y Loayza (2000) es de 2,4 .

- La variable de desarrollo financiero está expresada en ambos estudios en forma logarítmica.

- De esta manera la aceleración en la tasa de crecimiento del producto per cápita producto del desarrollo financiero en Chile entre 1961 y 2001 se obtiene de hacer la siguiente operación: Parámetro estimado*(ln(33,7)- $\ln (18,1))$.

- Finalmente, ocupando los valores promedio arrojados al utilizar los parámetros de ambos estudios mencionados se llega a la contribución de 1,5\% al crecimiento del producto per cápita, como consecuencia del desarrollo financiero entre 1961 y 2001.

- A su vez, el desarrollo financiero promedio en Chile en 1986, medido como crédito privado como proporción del PIB, fue de 47,7\%, mientras que el desarrollo financiero promedio en Chile entre 1986 y 2001 fue 56,4\%.

- De esta manera la aceleración en la tasa de crecimiento del producto per cápita como consecuencia del desarrollo financiero en Chile entre 1986 y 2001 se obtiene de hacer la siguiente operación: Parámetro estimado*(ln(56,4)-ln(47,7)).

- Del mismo modo, ocupando los valores promedio arrojados al utilizar los parámetros de ambos estudios mencionados se llega a la contribución de $0,4 \%$ al crecimiento del producto per cápita como consecuencia del desarrollo financiero entre 1986 y 2001. 
TABLA N ${ }^{\circ}$ 1: $\quad$ EFECTO SOBRE EL CRECIMIENTO DEL PRODUCTO PER CÁPITA DE ALCANZAR UN MAYOR DESARROLLO DEL SISTEMA FINANCIERO (puntos porcentuales por año)

\begin{tabular}{ccl}
\hline País & Crédito privado & Efecto sobre el crecimiento del PIB per cápita si \\
& $(\%$ PIB $)$ & Chile lograra un desarrollo financiero al nivel de:
\end{tabular}

\begin{tabular}{lrl}
\hline Suiza & 161 & $2,0 \%$ \\
Hong Kong & 157 & $1,9 \%$ \\
Estados Unidos & 145 & $1,7 \%$ \\
Malasia & 138 & $1,6 \%$ \\
Corea & 133 & $1,5 \%$ \\
Reino Unido & 132 & $1,5 \%$ \\
Singapur & 122 & $1,3 \%$ \\
Alemania & 120 & $1,3 \%$ \\
Nueva Zelanda & 112 & $1,1 \%$ \\
Australia & 90 & $0,5 \%$ \\
Francia & 87 & $0,5 \%$ \\
Canadá & 82 & $0,3 \%$ \\
Italia & 77 & $0,2 \%$ \\
Chile & 72 & $0,0 \%$ \\
\end{tabular}

Fuente: Elaboración propia en base a parámetros estimados en Levine, Loayza y Beck (2000) y Beck, Levine y Loayza (2000).

Como se explicó más arriba, el grado de desarrollo financiero de Chile es todavía menor que el existente en las economías desarrolladas, por lo que aún quedan espacios para alcanzar un mayor desarrollo del sistema financiero y con ello afectar positivamente al crecimiento económico. De hecho, como se aprecia en la Tabla $\mathrm{N}^{\circ} 1$, las ganancias en términos de crecimiento económico, de seguir desarrollando nuestro sistema financiero, pueden ser significativas. A modo de ejemplo, si Chile tuviera el desarrollo financiero como el de Australia podría acelerar su tasa de crecimiento del producto per cápita en 0,5\% por año; si tuviera el desarrollo financiero del Reino Unido o de Corea lo haría en $1,5 \%$ por año, mientras que si tuviera el desarrollo financiero de Suiza aumentaría su tasa de crecimiento del producto per cápita en $2,0 \%$ por año ${ }^{12}$.

${ }^{12}$ Ceteris paribus, esto es, se trata de efectos parciales que se obtienen sólo del aumento en la profundidad financiera (todos los otros determinantes del crecimiento se asumen constantes). Como en el mundo real muchas variables cambian al mismo tiempo (ej., el nivel educacional de la población aumenta con el ingreso per cápita y los países más ricos tienden a crecer más lento debido a la convergencia en el largo plazo de las tasas de crecimiento de los países), lo más probable es que en la práctica Chile no crecería a la tasa actual, más de $2 \%$ por año, aun si aumentara su profundidad financiera al nivel de Suiza. 


\section{Evaluación de propuestas recientes}

A pesar del notable desarrollo del sistema financiero en Chile durante los últimos treinta años, todavía existen desafíos pendientes que permitirían ganar en eficiencia en la asignación de recursos y con ello contribuir al crecimiento económico. Durante los últimos treinta años Chile ha logrado crear una institucionalidad que le permite tener un sistema bancario robusto (ver Gráfico $\mathrm{N}^{\mathrm{o}} 11$ ) y ha avanzado en aumentar la profundidad de su sistema financiero. El paso siguiente debiera ser avanzar en el desarrollo microeconómico del sistema financiero, aumentando el grado de sofisticación de los mercados e instrumentos del sistema, y seguir reduciendo la vulnerabilidad de la economía a los shocks externos.

En esta sección nos centramos en analizar dos espacios donde se puede mejorar. El primero es el problema de la liquidez del mercado accionario y el segundo se refiere al desarrollo de la industria de capital de riesgo. Pese a que existen otras áreas del sistema financiero donde se puede mejorar, por razones de espacio tratamos estos dos temas porque han sido considerados prioritarios por las autoridades políticas y en la actual coyuntura han estado en la discusión pública. También analizamos, brevemente, el rol que podría jugar el sistema financiero en disminuir la vulnerabilidad de la economía a reversiones repentinas en los flujos de capitales debido a shocks externos transitorios. Finalmente, también analizamos si la Reforma al Mercado de Capitales II propuesta va en la dirección de solucionar estos problemas y de seguir mejorando el funcionamiento del sistema financiero chileno.

\section{IV.1. Liquidez del mercado accionario}

Entre las causas de la falta de liquidez en los mercados se puede mencionar las asimetrías de información y los costos de transacción. Las primeras generan incertidumbre sobre el verdadero valor de los activos subyacentes, mientras que los costos de transacción crean un diferencial entre el precio pagado por el comprador y el precio recibido por el vendedor. Estas dos imperfecciones de mercado disminuyen el incentivo de los agentes a transar frecuentemente en el mercado.

Uno de los canales por los cuales el sistema financiero contribuye al crecimiento es a través de proveer liquidez: inversionistas que quieren estar líquidos se encuentran dispuestos a invertir sólo si los intermediarios les garantizan un mínimo de liquidez. En otras palabras, algunos proyectos de alto retorno requieren un compromiso de capital de largo plazo, pero los 
ahorrantes no quieren renunciar al control de sus ahorros por largos períodos. Por lo tanto, si el sistema financiero no provee suficiente liquidez para las inversiones de largo plazo, es probable que ocurra menos inversión en proyectos de alto retorno ${ }^{13}$.

Chile se caracteriza por tener mercados poco líquidos en relación con otras economías emergentes. Esta característica se presenta, por ejemplo, en el mercado de deuda del sector público y, especialmente, en el mercado accionario ${ }^{14}$. Como se describió en la sección III.2, Chile, a pesar de tener un mercado accionario "grande" en relación con otras economías emergentes, cuenta con un mercado tremendamente ilíquido, tendencia que se ha acrecentado a partir de mediados de los 90 .

Entre los argumentos que se mencionan en la literatura para explicar la poca liquidez del mercado accionario en Chile se encuentran: el encaje a los flujos de capitales (ADR secundarios), el impuesto a las ganancias de capital, y la alta concentración de mercado y el comportamiento tipo "manada"15 (con similares estrategias de inversión) de los Fondos de Pensiones (Cifuentes, Desormeaux y González, 2002) ${ }^{16}$.

La Reforma al Mercado de Capitales I (RMKI) estuvo orientada a aumentar el grado de competencia del sistema financiero y la liquidez del mercado accionario. Entre las medidas que se incorporaron se encuentran la creación de los multifondos y la competencia en la administración del ahorro previsional voluntario (APV), la desregulación de la industria de fondos mutuos y de seguros, la exención de impuestos a la venta corta, y una significativa reducción del impuesto sobre las ganancias de capital (para acciones con presencia bursátil) y sobre los ingresos por intereses de los inversionistas extranjeros. Previamente, en 1998 se había eliminado el encaje a los flujos de capitales.

Estas medidas son un claro avance en mejorar el funcionamiento del sistema financiero y con ello influenciar positivamente en la asignación de

${ }^{13} \mathrm{El}$ argumento implícitamente asume que los fondos internos de la firma y los que pueden proveer los actuales dueños a través de la suscripción de nuevas emisiones, lo que les permitiría realizar inversiones sin diluir el control de la propiedad, son insuficientes para realizar todos los proyectos con VPN positivo. Así, la mayor liquidez del mercado (secundario) es un requisito para atraer a otros inversionistas potenciales, quienes aportarían los fondos faltantes.

${ }^{14}$ Ver Fondo Monetario Internacional (2004).

${ }^{15}$ Comportamiento tipo manada se refiere a que las AFP actúan en bloque al momento de decidir su estrategia de inversión. Esto sucede porque la rentabilidad mínima que se le exige a cada AFP se calcula considerando la rentabilidad obtenida por el sector.

${ }^{16}$ Es necesario aclarar que aquí no se está juzgando si el encaje a los ADR o el impuesto a las ganancias de capital son una buena o mala política; sólo se mira desde una perspectiva de equilibrio parcial y de sus efectos sobre la liquidez del mercado accionario y sobre la industria de capital de riesgo. 
recursos y en el crecimiento de la economía. En particular, la creación de los multifondos, las exenciones a las ganancias de capital y la mayor competencia en el sistema financiero, promovida en la Reforma al Mercado de Capitales I, debieran contribuir a reducir los costos de transacción y las asimetrías de información y, con ello, a aumentar la liquidez del mercado ${ }^{17}$. Al respecto cabe destacar que las cifras más recientes aún no muestran un cambio claro (de tendencia) en la liquidez del mercado accionario - la tasa de rotación como porcentaje de la capitalización fue de 8,3\% en el año 2002 y de 11,2\% en el 2003, ambas cifras inferiores a las registradas en 1995-, pero se espera que sus efectos se materialicen crecientemente en el tiempo.

Sin embargo, todavía existen problemas de oferta, demanda y falta de desarrollo de la infraestructura del mercado que impiden aumentar la liquidez del mismo (Fondo Monetario Internacional 2004). Por el lado de la oferta existe una alta concentración en la propiedad de las firmas, con los consecuentes problemas de gobiernos corporativos y escasa divulgación de información relevante. Por el lado de la demanda también existe una alta concentración de mercado - los fondos invertibles son canalizados por seis AFP, las que tienen además políticas de inversión muy homogéneas-. Más allá de estos factores estructurales, la falta de liquidez del mercado accionario se relaciona con problemas en la infraestructura del mismo, como son la falta de estandarización de contratos e instrumentos, la falta de incorporación en la ley de conceptos de "neteo", "novación de obligaciones" e "irreversibilidad" y problemas con la entrega de información relevante por parte de las compañías ${ }^{18}$.

Beck y Levine (2004) estiman el efecto de la liquidez del mercado accionario sobre el crecimiento económico. Ocupando los parámetros estimados por estos autores se puede cuantificar las ganancias potenciales, en términos de crecimiento del producto per cápita, de un aumento de la liquidez del mercado accionario chileno. Chile tiene actualmente (al año 2001) una tasa de rotación en su mercado accionario, como porcentaje de la capitalización, de 8,6\%. Si aumentara la liquidez del mercado al nivel de la media (42\%) de una muestra de 86 países desarrollados y en desarrollo ${ }^{19}$, el aumento en la tasa de crecimiento del producto per cápita chileno sería de 1,5\% por año. En la Tabla $N^{\circ} 2$ se muestran los efectos sobre el crecimiento del producto per cápita en Chile si nuestro país aumentara el nivel de liqui-

17 Bondarenko (2001) explica cómo la mayor competencia en el sistema financiero lleva a una reducción de los costos de transacción y asimetrías de información y, con ello, a un aumento en la liquidez del mercado.

${ }^{18}$ Ver sección IV.3 para más detalle.

${ }^{19}$ Muestra usada por Beck y Levine en su estudio. 
TABLA N ${ }^{\circ}$ 2: $\quad$ EFECTO SOBRE EL CRECIMIENTO DEL PRODUCTO PER CÁPITA SI CHILE AUMENTARA LA LIQUIDEZ DEL MERCADO ACCIONARIO HASTA EL NIVEL DE OTRAS ECONOMÍAS SELECCIONADAS

\begin{tabular}{cc}
\hline País & Liquidez mercado accionario \\
(Tasa de rotación \% & Efecto sobre el crecimiento del \\
capitalización) & PIB per cápita si Chile aumentara \\
& la liquidez hasta el nivel de otras \\
& economías seleccionadas \\
& (Puntos porcentuales por año)
\end{tabular}

$\begin{array}{lrr}\text { Australia } & 75 & 2,1 \\ \text { Brasil } & 45 & 1,6 \\ \text { Chile } & 9 & - \\ \text { China } & 76 & 2,1 \\ \text { Alemania } & 142 & 2,7 \\ \text { Indonesia } & 85 & 2,2 \\ \text { Japón } & 79 & 2,1 \\ \text { México } & 69 & 2,0 \\ \text { Venezuela } & 30 & 1,2 \\ \text { Media 86 países } & 42 & 1,5\end{array}$
(2004).

Fuente: Elaboración propia en base a parámetros estimados en Beck y Levine

dez de su mercado accionario hasta los niveles de otras economías emergentes y desarrolladas seleccionadas. Como se aprecia, las ganancias pueden ser sustanciales.

\section{IV.2. El desarrollo de la industria de capital de riesgo}

Para impulsar el desarrollo económico es clave la proliferación de empresas innovadoras con alto potencial de crecimiento. Sin embargo, esta condición de innovadoras les otorga también un alto grado de riesgo asociado. En países con mercados de capitales profundos, la industria de capital de riesgo provee fondos para el surgimiento de dichas empresas. En economías en desarrollo, sin embargo, el subdesarrollo del sistema financiero presenta una barrera considerable para el surgimiento de estas empresas, en un contexto en que se exacerban imperfecciones de mercado asociadas a problemas de información, de monitoreo y control. Esta situación, junto a la existencia de potenciales externalidades de ganancias en productividad originadas en los sectores más innovadores, ha llevado a un razonamiento económico que justifica la intervención gubernamental, ya sea por medio de incentivos al sector privado o por la inyección directa de fondos públicos. 
La experiencia internacional, además, es consistente con este planteamiento. Por ejemplo, en Estados Unidos durante los últimos 20 años el gobierno ha utilizado diversos mecanismos, tanto incentivos tributarios como aportes directos de fondos públicos, para promover el desarrollo de la industria de capital de riesgo ${ }^{20}$. Las perspectivas indican que ese país continuará aumentando los incentivos tributarios, debido a la creciente importancia que el gobierno y los legisladores otorgan a esta industria como motor de creación de empleos, innovación tecnológica y crecimiento económico (Arrau, 2002). En resumen, pareciera existir un consenso entre los analistas (apoyado por la evidencia internacional) acerca de la necesidad de impulsar el desarrollo de la industria de capital de riesgo. Esto, porque se trata de empresas con un alto potencial de crecimiento donde existen externalidades positivas para la sociedad en términos de ganancias en productividad y eficiencia. Así, la innovación que se produce en estas empresas permite generar nuevas tecnologías que pueden ser aprovechadas por toda la sociedad. Pero, como estas empresas no internalizan completamente el beneficio social del desarrollo de tales tecnologías, surge la necesidad de dar apoyo estatal al desarrollo de esta industria.

La experiencia en Chile para desarrollar la industria de capital de riesgo ha tenido dos intentos fallidos. El primer intento ocurrió en 1989, cuando se dio vida a tres fondos de inversión no rescatables (Fondos de Inversión Mobiliarios, Fondos de Inversión Inmobiliarios y Fondos de Inversión de Capital de Riesgo) cuyas cuotas de participación podrían servir de instrumento de inversión para los Fondos de Pensiones. A tres años de introducida esta modificación sólo se habían formado dos Fondos de Capital de Riesgo, los que no invertían en capital de riesgo clásico, sino más bien en empresas que se encontraban en etapas más avanzadas de su desarrollo.

El segundo intento por desarrollar la industria en Chile se produjo entre los años 1994 y 1995. En particular, se flexibilizaron algunas normas de los Fondos de Capital de Riesgo y se crearon los Fondos de Inversión de Capital Extranjero de Riesgo. Además, CORFO implementó un programa para incentivar el desarrollo del capital de riesgo, otorgando financiamiento a pequeñas y medianas empresas ya sea vía aportes de capital o préstamos convertibles en acciones.

No obstante estos esfuerzos, la industria no prosperó porque persistieron problemas de gobierno corporativo y estructurales como, por ejem-

${ }^{20}$ En particular, se realizaron modificaciones tributarias concediendo beneficios en los años 1993, 1997 y 1998, mientras que actualmente se encuentran en el Congreso nuevas modificaciones de carácter tributario (Arrau, 2002). 
plo, inflexibilidades en el diseño de contratos (límites en la propiedad de los proyectos o empresas), bajas comisiones para las administradoras, límite máximo para los aportantes, administradoras pasivas en la gestión de los proyectos, etc. (Arrau, 2002). En suma, hubo un exceso de regulación para proteger a los Fondos de Pensiones y problemas de gobierno corporativo.

La conclusión básica de los puntos anteriores es que los intentos para estimular la industria de capital de riesgo en Chile han tenido una falla originaria básica: las reformas legales han estado orientadas a ofrecer nuevos instrumentos de inversión para los Fondos de Pensiones y no han estado motivadas por el objetivo de generar una industria de financiamiento de empresas nuevas o en etapas tempranas de desarrollo.

Hoy en Chile la industria de capital de riesgo se encuentra estancada en un nivel muy incipiente de desarrollo. De hecho, casi el único sector que aporta recursos a la industria son los Fondos de Pensiones, concentrando alrededor del $80 \%$ del total de los aportes. Esta característica contrasta con la estructura de financiamiento de, por ejemplo, Estados Unidos, donde inversionistas extranjeros, empresas, fundaciones, personas naturales y compañías de seguros participan mucho más activamente como financistas. Este comportamiento se explica, en parte y como se dijo, porque los Fondos de Inversión de Capital de Riesgo fueron especialmente creados durante la década de los noventa para los Fondos de Pensiones, con el propósito de aumentar la diversificación de su cartera. Pero, por su naturaleza, los Fondos de Pensiones tienden a favorecer inversiones de largo plazo y poco riesgosas $^{21}$. De hecho, Bygrave y Timmons (1992) recomiendan evitar usar a los Fondos de Pensiones como principal financista de capital de riesgo clásico, ya que éstos sesgan las inversiones hacia empresas en etapas más avanzadas de desarrollo, reduciendo la iniciación de empresas y las inversiones en empresas en etapas tempranas de desarrollo. Esto es justamente lo que ha sucedido en Chile: la naturaleza de los Fondos de Pensiones (ahorro previsional obligatorio) ha llevado a que las inversiones en capital de riesgo se canalicen preferentemente al financiamiento de empresas y proyectos que se encuentran en etapas de desarrollo más avanzadas, en desmedro del capital de riesgo "semilla", que es la etapa inicial del otorgamiento de recursos para ideas o proyectos innovadores y donde existe mayor riesgo. Además, la predominancia de los Fondos de Pensiones genera una carga regulatoria excesiva. Junto a lo anterior influyen en el poco desarrollo de esta industria los bajos y negativos retornos obtenidos hasta

${ }^{21}$ Los Fondos de Pensiones posiblemente necesitarían acompañar su inversión con el uso de derivados que les permitan acotar las potenciales pérdidas. 
ahora en las inversiones realizadas, la iliquidez de las cuotas aportadas, la inexistencia de mecanismos expeditos para recuperar los montos invertidos y la falta de incentivos tributarios como los existentes en otros países.

En relación con esto último, de acuerdo a Gompers y Lerner (1999), la rebaja en la tasa de impuesto a las ganancias de capital tiene importantes efectos sobre los fondos levantados para capital de riesgo, porque aumenta la rentabilidad esperada tanto para los oferentes como para los demandantes de capital ${ }^{22}$.

En el caso de Chile, la Reforma al Mercado de Capitales I estipuló que las acciones de empresas emergentes quedaran exentas de pagar impuesto a las ganancias de capital, cuando dicha ganancia se materialice (venta en bolsa). Sin embargo, este beneficio no se hizo extensivo a los fondos de inversión; vale decir, cuando el fondo distribuya el retorno a los tenedores de cuotas, éstos deberán pagar el impuesto a las ganancias de capital, situación que desincentiva la inversión en cuotas de fondos de inversión privados. Para solucionar esto se requiere que este beneficio, propio de las acciones emitidas en la bolsa emergente, sea extendido a aquellos financistas que financian las empresas nacientes a través de fondos de inversión de capital de riesgo. Además, la exención del impuesto a las ganancias de capital se limitó a los tres años que comienzan con la apertura de la empresa en la bolsa emergente, pero no incluye el aumento de valor desde que la empresa se crea hasta que se coloca en bolsa, que es el momento de mayor creación de valor. Finalmente, las tasas de impuestos marginales, que alcanzan hasta $43 \%$, son extremadamente altas comparadas con las existentes en Estados Unidos y Europa ${ }^{23}$.

\section{IV.3. Reduciendo la vulnerabilidad externa: ¿Un problema financiero?}

Aunque Chile ha avanzado de manera importante en las últimas décadas en alcanzar estabilidad macroeconómica y en el fortalecimiento de sus instituciones, su ciclo económico sigue dependiendo fuertemente de los

\footnotetext{
${ }^{22}$ Cabe destacar que Keuschnigg y Soren Nielsen (2003) concluyen que el impuesto a las ganancias de capital causa pérdidas de bienestar.

${ }_{23}$ Arrau (2002), a modo de ejemplo, explica que Bill Gates, habiendo obtenido una ganancia de capital personal de US\$204 millones al abrir Microsoft a la bolsa (Nasdaq) en 1986, habría tenido que pagar en Chile una tasa marginal del 43\%, mientras que en Estados Unidos le corresponde 20\% de impuesto. El caso de Jim Clark es aún más impresionante: en 18 meses incrementó su patrimonio personal desde US\$ 5,6 millones hasta US\$ 273 millones, desde que fundó Netscape en abril de 1994, hasta que la llevó a la bolsa. En EE.UU. le corresponde 14\% de impuesto, mientras que en Chile habría pagado $43 \%$.
} 
shocks externos y sus efectos sobre el precio de los commodities. De hecho, Caballero (2002) muestra que en Chile existe una alta correlación entre el ciclo económico y los shocks a los términos de intercambio, en contraste con lo que sucede en otras economías exportadoras de commodities, como Australia o Noruega. Además, Caballero (2002) y Caballero et al. (2004) argumentan que la incapacidad de la economía chilena de suavizar shocks transitorios a los términos de intercambio tiene como raíz un problema financiero.

Es plausible pensar que la mayor volatilidad del producto asociada a esta incapacidad de suavizar shocks transitorios podría afectar al crecimiento de largo plazo. Esto, porque existen altos costos asociados a la creación y cierre (quiebra) de firmas. Así, ceteris paribus, los empresarios van a preferir un ambiente donde los ciclos económicos sean menos pronunciados. De este modo, se concluye, la mayor volatilidad del producto afectaría negativamente a la tasa de inversión de la economía y por lo tanto al crecimiento de largo plazo.

El mecanismo a través del cual los shocks externos afectan a la economía chilena se puede caracterizar de la siguiente manera: primero, un shock externo adverso, por ejemplo a los términos de intercambio, eleva la necesidad de recursos externos, los que se necesitan para suavizar tal shock, de modo que la demanda agregada interna no se vea afectada. Sin embargo, el shock gatilla justamente la respuesta opuesta por parte de los inversionistas internacionales; éstos retiran sus capitales justo cuando la economía más los necesita. En segundo lugar, una vez que los mercados financieros internacionales fallan en acomodar las necesidades financieras de las firmas y consumidores locales, éstos se vuelcan al mercado financiero doméstico y, en particular, a los bancos comerciales. Pero este incremento en la demanda de fondos no es acomodado con un incremento en la oferta por parte de los bancos (particularmente los bancos extranjeros que operan en el medio local), los cuales contraen el crédito doméstico e incrementan su posesión neta de activos externos, contribuyendo así a amplificar la escasez de recursos financieros. Caballero et al. (2004) muestran que justamente esto fue lo que sucedió en Chile durante las recientes crisis de Asia y Rusia.

La pregunta relevante que surge entonces se refiere al rol que puede jugar el sistema financiero doméstico para disminuir esta vulnerabilidad externa y, con ello, contribuir al crecimiento de largo plazo de la economía. Al respecto cabe señalar que la escasez de capitales externos en momentos de crisis depende en definitiva de la disposición de los inversionistas extranje- 
ros para proveer recursos que permitan suavizar los shocks externos transitorios. Además, y dado que los shocks externos (como una caída de los términos de intercambio) son shocks agregados que afectan a la economía como un todo, éstos no se pueden diversificar al interior del país, sino que deben diversificarse con el resto del mundo. Por lo tanto, la capacidad de suavizar estos shocks también depende de la disposición de los inversionistas extranjeros para compartir el riesgo asociado a las fluctuaciones de los términos de intercambio, por ejemplo a través de la compra y venta de seguros. La disposición de los inversionistas internacionales a prestar y compartir riesgos depende de la confianza de éstos en el país, lo que depende de nuestras instituciones y políticas económicas.

El sistema financiero puede aportar en fortalecer las instituciones de la economía, por ejemplo, a través del fortalecimiento de la regulación y supervisión del sistema bancario, pero el desarrollo de políticas e instituciones va mucho más allá de las instituciones del sistema financiero, e incluyen también la estabilidad macroeconómica con una inflación baja y estable y cuentas fiscales ordenadas, el respeto de los derechos de propiedad, un bajo nivel de corrupción, una regulación adecuada, etc. En este sentido, luego de las crisis de Asia y Rusia, Chile ha seguido implementando reformas financieras ${ }^{24}$ y en otras áreas de la economía; por ejemplo, la Reforma al Mercado de Capitales de 2001 y la consolidación de la estabilidad macroeconómica, con la adopción de un tipo de cambio flexible, de una regla fiscal de superávit estructural y un esquema de metas de inflación completo. Estos avances debieran contribuir a reducir la vulnerabilidad de la economía chilena a reversiones repentinas en los flujos de capitales observadas en el pasado, a través de fortalecer la institucionalidad y estabilidad económica del país y, con ello, aumentar el grado de confianza de los inversionistas institucionales en el funcionamiento de nuestra economía.

\section{IV.4. La Reforma al Mercado de Capitales II}

Como se mencionó, el sistema financiero chileno ha sufrido una profunda transformación durante las tres últimas décadas y en los últimos años Chile ha seguido perfeccionando su sistema financiero, con reformas orientadas principalmente a aumentar su grado de sofisticación y a mejorar su funcionamiento a nivel microeconómico. La Ley de Opas del año 2001 tuvo

\footnotetext{
${ }^{24}$ Ver sección III.
} 
como su punto principal regular (proteger) los derechos de los accionistas minoritarios y mejorar los gobiernos corporativos, mientras que la Reforma al Mercado de Capitales I se centró en promover el ahorro nacional y la competencia del mercado financiero. Estas reformas son un claro avance en mejorar el funcionamiento del sistema financiero y con ello influir positivamente en la asignación de recursos y en el crecimiento de la economía.

La Reforma al Mercado de Capitales II propuesta (RMKII), al igual que la RMKI y la Ley de Opas, también apunta en la dirección de mejorar el funcionamiento del sistema financiero. En particular, la RMKII incluye incentivos para el desarrollo de la industria de capital de riesgo:

- Pone incentivos tributarios a las ganancias de capital:

- Se elimina la distorsión tributaria aludida, que desfavorece la inversión a través de fondos de inversión vis-à-vis con los activos subyacentes de manera directa. Ahora los ingresos por rentas exentas de impuestos de los activos subyacentes que mantienen los fondos de inversión podrán ser traspasados a los tenedores de cuotas del fondo.

- Se exime del pago de impuesto a las ganancias de capital obtenidas por los tenedores de acciones de sociedades que, cumpliendo ciertos requisitos de formación preliminar de precios, enajenen sus acciones en bolsa o vendan parte de su capital accionario a una persona no relacionada con los principales accionistas de la sociedad. La ganancia de capital exenta tendrá un límite de UF 10.000 por accionista. Esta medida, si bien se aplica a todas las acciones y no sólo a las de capital de riesgo, tiene como objetivo promover el desarrollo de proyectos innovadores al aumentar el retorno de estas inversiones ${ }^{25}$.

- $\quad$ Establece garantías para los Fondos de Inversión de Capital de Riesgo.

- Crea una forma de organización más flexible (sociedad de responsabilidad limitada por acciones) que posibilitará controlar decisiones de una sociedad sin necesidad de ser accionista mayoritario o llamar a junta de accionistas.

Se flexibiliza la Ley de Prendas, la que se espera promoverá el acceso al crédito competitivo a muchas empresas pequeñas.

Estas medidas, junto con otras que no se analizan en esta sección — pero que apuntan en la misma dirección—, debieran ayudar a mejorar el

${ }^{25}$ La reforma propuesta amplía el beneficio existente en RMKI a otro tipo de sociedades (sociedades por acciones y sociedades anónimas cerradas), sin plazo pero con un límite de UF 10.000 . 
funcionamiento del sistema financiero, fomentando el ahorro y la inversión, en particular por:

- la profundización de las reformas de perfeccionamiento de los gobiernos corporativos;

- el fortalecimiento de los mecanismos de ahorro previsional voluntario, $y$

- el fortalecimiento de los mecanismos de fiscalización, potestades de control, sanción y coordinación, para evitar en el futuro casos como el de Corfo/Inverlink.

Si bien resulta prematuro hacer una evaluación definitiva de las reformas propuestas, es obvio que éstas apuntan en la dirección correcta. Sin embargo, es difícil evaluar si las reformas implementadas en los últimos años y aquellas propuestas en la Reforma al Mercado de Capitales II son suficientes. La dificultad de establecer un equilibrio óptimo entre regulación, supervisión y liberalización del sistema financiero, junto con el gran dinamismo que han alcanzado los mercados financieros debido al creciente proceso de globalización de las economías, obligan a evaluar constantemente las reformas implementadas y debatir acerca de las reformas pendientes que podrían ayudar en avanzar hacia un sistema financiero más desarrollado. En suma, el proceso de reformas es de naturaleza continua. A continuación se exponen algunas propuestas de reformas pendientes que pueden ser útiles para guiar la discusión futura de hacia dónde avanzar en esta materia.

Algunos analistas han planteado la necesidad de seguir avanzando en liberalizar el sistema financiero y en reducir la carga tributaria que lo afecta, por ejemplo aumentando la exención tributaria a las ganancias de capital en inversiones en capital de riesgo y eliminando el impuesto al cheque. Arrau (2003) plantea que es necesario incentivar una mayor competencia en la administración — de una parte - de los ahorros forzosos para la vejez y en la provisión de algunos servicios de apoyo al giro bancario ${ }^{26}$. El mismo autor (Arrau, 2004) plantea que, considerando la experiencia de otros países, la exención propuesta de UF 10.000 (US\$ 268.000 aproximadamen$\mathrm{te}^{27}$ ) para las ganancias de capital en inversiones de capital de riesgo resulta insuficiente (en Irlanda esta exención alcanza los US\$ 10 millones). Por último, este autor sostiene que el episodio Corfo-Inverlink significó un re-

\footnotetext{
${ }^{26}$ Redbank, Transbank y Centro de Compensación Automatizado, CCA.

${ }^{27}$ Usando el tipo de cambio de cierre del 28 de junio de 2004.
} 
troceso hacia un sistema de mayores controles y prohibiciones, en vez de avanzar a un sistema que fortalezca la disciplina de mercado y el autocontrol de los agentes partícipes, pero donde hay fuertes sanciones para quienes transgredan el espíritu de las normas y abusen de la confianza del público.

Con respecto a la falta de liquidez del mercado, el Fondo Monetario Internacional propone medidas complementarias destinadas a solucionar este problema. A modo de ejemplo se pueden mencionar las siguientes ${ }^{28}$ :

- Fortalecer los fundamentos legales para los contratos y liquidación de activos. Se necesita fortalecer tales fundamentos a través de incorporar más firmemente en la ley los conceptos de "carácter definitivo" (término incondicional e irrevocable de las transacciones), "neteo" (compensación de créditos y débitos entre partes involucradas en una serie de transacciones que involucran el mismo instrumento) y "novación de una obligación” (la sustitución de una obligación o deudor viejo por una nueva obligación o deudor).

- Modernizar la liquidación de instrumentos, estandarizar los contratos y mejorar los métodos de valoración de instrumentos (por ejemplo, uniformando los métodos usados y mejorando la información de precios).

- Revisar las políticas impositivas al sector financiero. Existen impuestos distorsionadores, como el de timbre y estampillas, que eleva el costo de emitir bonos, y una excesiva complejidad en la aplicación y diseño del impuesto a las ganancias de capital y sus exenciones, haciendo difícil evaluar sus efectos en los incentivos.

- Fortalecer los reportes financieros de las compañías listadas en bolsa y adecuarlos a los estándares internacionales (International Financial Reporting Standards).

- Existen debilidades en materia de regulación, supervisión, herramientas de resolución y ejecución; falta avanzar en el monitoreo de conglomerados financieros y establecer reglas para su operación, así como una mejor capacidad de supervisión basada en riesgo.

Un tema que se ha dejado de lado en la discusión de la RMKI y de la RMKII es el referente al desarrollo del mercado de derivados en Chile. El desarrollo de este mercado puede también tener efectos positivos sobre la liquidez, ya que, a modo de ejemplo, las AFP posiblemente transarían más

${ }^{28}$ Para leer las propuestas específicas ver "Financial Sector Assessment Program”, FMI (2004). 
frecuentemente en el mercado accionario si hubiese un mercado de opciones donde pudiesen transar para acotar sus riesgos ${ }^{29}$.

Por otra parte, la posición externa del sector privado (activos menos pasivos) se ha fortalecido en los últimos años. A pesar de esto, la posición neta de pasivos es aún substancial y está expuesta a riesgos debidos a las fluctuaciones en el tipo de cambio. Este hecho, junto con el incremento en la volatilidad cambiaria producto de la flotación, ha resultado en un marcado incremento en la cobertura cambiaria con contratos forwards. El volumen de comercio de forwards de tipo de cambio se ha duplicado entre 1994 y 2004, y relativo al PIB el mercado es grande cuando se compara con otras economías emergentes. La cobertura con contratos forwards alcanza un $42 \%$ en el sector corporativo, entre $90 \%$ y $100 \%$ en el sector bancario y $50 \%$ en los Fondos de Pensiones. A pesar de esto, otros instrumentos de cobertura cambiaria como las opciones no tienen un mercado desarrollado, principalmente por el hecho de que a los bancos no se les permite suscribir opciones y por lo tanto no pueden intermediar entre compradores y vendedores.

En relación con la cobertura de riesgos de tasa de interés, no hay un mercado activo de derivados, por lo que existe una gran exposición a este riesgo en el sector financiero no bancario, particularmente en el sector de seguros de vida.

Así, son numerosos los ejemplos de necesidades de administración de riesgos que no son cubiertas hoy en Chile debido a la ausencia de derivados.

Chile todavía está en una etapa temprana de desarrollo del mercado de derivados y requiere alcanzar más diversidad y complejidad de instrumentos para permitirles a los participantes manejar los riesgos más eficientemente. Los principales problemas y desafíos para el mercado de derivados en Chile se encuentran en las siguientes áreas:

i) Marco regulatorio y legal: A modo de ejemplo, a los Fondos de Pensiones no se les permite suscribir opciones, lo que impide que puedan cubrir sus portafolios de acciones. Del mismo modo, el sector bancario no puede escribir y vender opciones, lo cual es incoherente con un sistema financiero que evoluciona desde la "administración de reglas" hacia la "administración de riesgos”. Esta restricción también impide que los bancos puedan intermediar opciones, impidiendo el desarrollo del mercado.

ii) Falta de una infraestructura de mercado: Los derivados son instrumentos complejos, por lo que las ganancias en eficiencia al usarlos depende

${ }^{29}$ A modo de ejemplo, una AFP no puede hoy cubrir su portafolio de acciones contra una baja en el precio de éstas suscribiendo opciones, tanto por la falta de instrumentos como porque existen restricciones a las actividades de los Fondos de Pensiones. 
de tener una adecuada supervisión. La liberalización requiere asegurarse de que las instituciones supervisoras tengan un adecuado conocimiento del mercado. También es necesario fijar reglas acerca de cómo medir los riesgos de los instrumentos derivados y el capital adecuado para resguardo de terceros, mientras que la adopción de estándares internacionales referentes al mercado de derivados permitiría una mayor participación de inversionistas extranjeros. Por otro lado, para fortalecer la infraestructura del mercado es necesario: i) definir el tratamiento impositivo, de valoración y contabilidad de los nuevos instrumentos derivados; ii) promover contratos estándar y códigos de conducta de la industria; iii) diseminar conocimientos de administración, datos de mercado y análisis; iv) coleccionar indicadores, como los volúmenes transados diarios por sector y por instrumento, y v) proveer de los datos al público para promover la competencia y evitar la manipulación.

Como un todo, las reformas introducidas en la RMKI y propuestas en la RMKII, sumadas a la Ley de Opas, van en la dirección correcta. Todas ellas permitirán un mejoramiento del funcionamiento del sistema financiero chileno, a través de mejorar los gobiernos corporativos y las cinco funciones que presta el sistema financiero a la economía, las que fueron descritas en la sección II. Como se explicó, todo esto debiera impactar en las decisiones de ahorro e inversión y, con ello, impulsar el crecimiento de la economía. Sin embargo, es difícil evaluar si estas reformas son suficientes, en parte porque aún no existe consenso sobre el estándar que los países deben alcanzar en estas materias. Por ejemplo, no hay consenso sobre la situación "ideal" en materia de regulaciones específicas, o sobre cuál debe ser la carga impositiva óptima. Más aún, es posible que estos consensos no se logren nunca por el gran dinamismo que muestran los mercados financieros, por lo que es necesario seguir innovando en estas materias constantemente.

\section{Resumen y conclusiones}

La literatura teórica y empírica ha llegado a un creciente consenso acerca del significativo impacto que tiene el desarrollo del sistema financiero en el crecimiento económico. Un sistema financiero más desarrollado afecta a las decisiones de inversión y ahorro, mejorando la asignación de recursos en la economía y, con ello, impulsando el crecimiento económico.

Chile ha experimentado una profunda transformación de su sistema financiero, desde la liberalización a mediados de los setenta, pasando por la crisis de la deuda de comienzos de los ochenta y el posterior reordenamien- 
to, hasta el período de crecimiento y profundización que se inició a mediados de los ochenta y continúa hasta hoy. Así, actualmente el sistema financiero chileno es uno de los más grandes entre las economías emergentes, aunque todavía no tiene el tamaño de aquellos de países desarrollados y de algunas economías emergentes de Asia.

Un problema puntual del sistema financiero chileno es la baja liquidez del mercado accionario; a pesar de ser un mercado relativamente grande, éste es tremendamente ilíquido. Otra área donde también existe un desafío importante es el desarrollo de la industria de capital de riesgo, tal que ésta permita desarrollar firmas con un alto potencial de crecimiento. También es necesario apoyar el desarrollo del mercado de derivados financieros.

Con respecto a la vulnerabilidad de la economía chilena a sufrir reversiones repentinas en los flujos de capitales, ésta depende de la disposición de los inversionistas internacionales para proveer recursos en momentos de crisis y para negociar contratos de seguros, lo cual se asocia con el grado de confianza de éstos en las políticas económicas e instituciones del país. Las reformas en el sector financiero y en otras áreas de la economía, introducidas en los años siguientes a las crisis de Asia y Rusia, debieran contribuir al fortalecimiento de la institucionalidad y estabilidad del país $y$, con ello, a aumentar la confianza de los inversionistas extranjeros en la economía chilena, disminuyendo de este modo la vulnerabilidad externa de nuestro país.

Las reformas de los últimos años (Ley de Opas y Reforma al Mercado de Capitales I), así como el proyecto de Reforma al Mercado de Capitales II, van en la dirección de solucionar algunas de estas falencias, incluyendo diversas medidas destinadas a mejorar el funcionamiento del sistema financiero, lo que debiera resultar en un impulso al ahorro, la inversión y el crecimiento futuro de nuestra economía. Aunque el poco tiempo transcurrido desde la implementación de estas reformas, así como la inexistencia de consensos relativos a estándares internacionales en temas regulatorios, impositivos y en otras materias relevantes, no permiten concluir si las reformas son suficientes, la rapidez con que evoluciona el mundo financiero — en particular dada la creciente globalización — sugiere que el esfuerzo de reforma debe ser constante. Esto es, el equilibrio entre mayor regulación/supervisión versus mayor libertad/competencia requiere un esfuerzo de búsqueda permanente. En esta misma línea se debe avanzar para resolver aquellas falencias que no han sido adecuadamente atendidas en la RMKI y RMKII. 


\section{REFERENCIAS}

Arrau, P.: "Agenda Pro Crecimiento: Propuestas de Reforma al Mercado de Capitales II". Manuscrito, Consultora Gerens, Chile, 2002.

Arrau, P.: “Un Mercado de Capitales Para Crecer”. En F. Morandé y J. Quiroz (eds.), Crecimiento en Chile, una Mirada desde los Sectores. Cámara Chilena de la Construcción, agosto, 2003.

Arrau, P.: “Mercado de Capitales II". En Suplemento Negocios, diario La Tercera, 19 de junio, p. 39, 2004.

Bagehot, W.: Lombard Street (1873). F. C. Genovese (editor). Homewood, Illinois: Richard D. Irwin, 1962.

Beck, T., A. Demirguç-Kunt y R. Levine: “A New Database on Financial Development and Structure”. Banco Mundial, 2003. Disponible en http://www.worldbank.org/ research/projects/finstructure/database.htm

Beck, T. y R. Levine: "Industry Growth and Capital Allocation: Does Having a Market or Bank-Based System Matter?”. En Journal of Financial Economics, 64 (2002): 147-180.

Beck, T. y R. Levine: “Stock Markets, Banks and Growth: Panel Evidence”. En Journal of Banking and Finance, 28 (3) (2004): 423-442.

Beck, T., R. Levine y N. Loayza: "Finance and the Sources of Growth". En Journal of Financial Economics, 58 (2000): 261-300.

Bondarenko, O.: "Competing Market Makers, Liquidity Provision, and Bid-Ask Spreads". En Journal of Financial Markets, 4 (3) (2001): 269-308.

Bygrave, W. y J. Timmons: Venture Capital at the Crossroads. Harvard Business School Press, 1992.

Caballero, R.: “Coping with Chile’s External Vulnerability: A Financial Problem”. En N. Loayza y R. Soto (eds.): Economic Growth: Sources, Trends, and Cycles. Banco Central de Chile, 2002.

Caballero, R., K. Cowan y J. Kearns: "Fear of Sudden Stops: Lessons from Australia and Chile”, NBER Working Paper No 10519, 2004.

Carlin, W. y C. Mayer: “Finance, Investment, and Growth”. En Journal of Financial Economics, 69 (1) (2003): 191-226.

Cifuentes, R., J. Desormeaux y C. González: “Capital Markets in Chile: From Financial Repression to Financial Deepening”. Documento de Política Económica N ${ }^{\circ} 4$, Banco Central de Chile, 2002.

Corbo, V., L. Hernández y F. Parro: "Institutions, Economic Policies and Growth: Lessons from the Chilean Experience”. Documento de Trabajo $N^{\circ} 317$, Banco Central de Chile, 2005.

Corbo, V. y K. Schmidt-Hebbel: "Efectos Macroeconómicos de la Reforma de Pensiones en Chile”. En Resultados y Desafíos de la Reforma al Sistema de Pensiones, Federación Internacional de Administradoras de Fondos de Pensiones (FIAP), 2003.

De Gregorio, J.: “Borrowing Constraints, Human Capital Accumulation, and Growth". En Journal of Monetary Economics, 37 (1) (February 1996): 49-71.

De Gregorio, J. y P. Guidotti: “Financial Development and Economic Growth”. En World Development, 23 (3) (1995): 433-448. 
Demirguç-Kunt, A. y R. Levine: "Financial Structure and Economic Growth: Perspective and Lessons”. En A. Demirguç-Kunt y R. Levine (eds.), Financial Structure and Economic Growth: A Cross-Country Comparison of Banks, Markets, and Development. Cambridge, MA: MIT Press, 2001a.

Demirguç-Kunt, A. y R. Levine: "Bank-Based and Market-Based Financial Systems: Cross-Country Comparisons”. En A. Demirguç-Kunt y R. Levine (eds.), Financial Structure and Economic Growth: A Cross-Country Comparison of Banks, Markets, and Development. Cambridge, MA: MIT Press, 2001b.

Demirguç-Kunt, A. y V. Maksimovic: "Law, Finance, and Firm Growth”. En Journal of Finance, 53 (1998), 2107-2137.

Fondo Monetario Internacional: "Financial Sector Assessment Program: Chile”. Mimeo, 2004.

Goldsmith, R. W.: Financial Structure and Development. New Haven, CT: Yale University Press, 1969.

Gompers, P. y J. Lerner: "What Drives Venture Capital Fundraising”. NBER Working Paper $\mathrm{N}^{\circ}$ 6909, 1999.

Gurley, J. G. y E. S. Shaw: "Financial Aspects of Economic Development”. En American Economic Review, 45 (1955): 515-538.

Japelli, T. y M. Pagano: “Saving, Growth and Liquidity Constraints”. En Quarterly Journal of Economics 109 (1) (1994): 83-109.

Keuschnigg, C. y Soren Nielsen: "Taxes and Venture Capital Support”. CESifo Working Paper $\mathrm{N}^{\circ}$ 1094, 2003.

King, R. G. y R. Levine: "Finance and Growth: Schumpeter Might Be Right". En Quarterly Journal of Economics, 108 (1993): 717-738.

La Porta, R., F. López de Silanes, A. Schleifer y R. Vishny: "Legal Determinants of External Finance”. En Journal of Finance, 52 (July) (1997): 1131-1150.

Levine, R.: "Financial Development and Economic Growth: Views and Agenda". En Journal of Economic Literature, 35 (1997): 688-726.

Levine, R.: “Bank-Based or Market-Based Financial Systems: Which Is Better?”. En Journal of Financial Intermediation 11 (2002): 398-428.

Levine, R.: "Finance and Growth: Theory, Evidence and Mechanisms". En P. Aghion y S. Durlauf (eds.), Handbook of Economic Growth. Amsterdam: North-Holland, 2004.

Levine, R., N. Loayza y T. Beck: "Financial Intermediation and Growth: Causality and Causes”. En Journal of Monetary Economics, 46 (2000): 31-77.

Levine, R. y S. Zervos: "Stocks Markets, Banks and Economic Growth". En American Economic Review, 88 (1998): 537-558.

Loayza, N. y R. Rancieres: "Financial Fragility, Financial Development, and Growth". Banco Mundial, mimeo, 2002.

Lucas, R.: “On the Mechanics of Economic Development”. En Journal of Monetary Economics, 22 (1988): 3-42.

McKinnon, R. I.: Money and Capital in Economic Development. Washington, DC: Brooking Institutions, 1973.

Miller, M.: “Financial Markets and Economic Growth”. En Journal of Applied Corporate Finance, 11 (1998): 8-14.

Rajan, R. G. y L. Zingales: "Financial Dependence and Growth”. En American Economic Review, 88 (1998): 559-586. 
Robinson, J.: The Rate of Interest and Other Essays. Londres: MacMillan, 1952.

Schumpeter, J.: The Theory of Economic Development. Traducción de R. Opie. Cambridge, MA: Harvard University Press, 1934.

Tadesse, S.: "Financial Architecture and Economic Performance: International Evidence”. En Journal of Financial Intermediation, 11 (2002): 429-454. 